\title{
Los invisibles del Real de Minas. \\ Reflexiones y propuestas en torno al sitio arqueológico de Nóvita Viejo, Alto San Juan-Chocó (Colombia). Siglos XVIII-XIX
}

Luis Francisco López C. *

"Cuando llegó, en el pueblo no había nadie. Las puertas y las ventanas
quedaron de par en par. El silencio era sepulcral"
El padre Janeiro Jiménez Atencio, luego de la masacre de Bojayá

(Neira 2002)

LÓPEZ C., L.F. Los invisibles del Real de Minas. Reflexiones y propuestas en torno al sitio arqueológico de Nóvita Viejo, Alto San Juan-Chocó (Colombia). Siglos XVIII-XIX. Revista do Museu de Arqueologia e Etnologia, São Paulo, 17: 391-417, 2007.

Resumo: Em meio dos conflitos e potencialidades que fazem de Choco um dos departamentos mais controvertidos da Colômbia, a possibilidade de levar a cabo uma intervenção arqueológica no antigo Real de Minas de San Francisco de Nóvita, hoje abandonado na selva mas vivo nas tradições locais e nos documentos de arquivo, constitui uma alternativa de interesse comunitário que não só permitiria ampliar nosso horizonte investigativo, mas também contribuiria para destacar com maior ênfase a grande riqueza cultural da região e, sobretudo, a imagem que se tornou invisível dos protagonistas de sua própria história. Este artigo busca fazer aproximações teóricas e metodológicas a partir de fontes primárias e alguns estudos adiantados em outros países.

Palavras-Chave: Nóvita Viejo - Real de Minas - Escravizados Transculturação - Arqueologia afrocolombiana.

finales de 1897 , la sociedad bugueña ${ }^{1}$ se estremeció de asombro cuando Luciano Rivera y Garrido, el autor de Impresiones y Recuerdos, divulgó la entrevista realizada por él mismo a una persona que durante treinta años había integrado las páginas de una novela

(*) Universidad Nacional de Colombia. fralopezca@gmail.com (1) De Buga, municipio del actual Departamento del Valle del Cauca, Colombia. romántica, cuyo fundamento histórico se confundía con el entorno legendario de un poeta nacido en Cali en abril de 1837. Miembro de una familia aventajada económicamente, al menos durante un tiempo, Jorge Isaacs escribió María apoyándose en recuerdos personales en los que era imposible pasar por alto las minas de oro y platino, las grandes haciendas y los centros urbanos decimonónicos que también constituían el escenario de hombres y mujeres cuyos ancestros habían 
sido arrebatados de sus territorios originales, la mayor parte de estos ubicados en el occidente de África, para luego ser vendidos y adquiridos como mercancía por efecto de la trata esclavista (Escalante 1964:65-110).

Para la gran mayoría de esas personas, se trataba de un proceso de explotación, aculturación, resistencia y mestizaje iniciado hacía más de dos siglos en las costas de Cartagena, el principal puerto "negrero" de entonces. Juan Angel Molina (Foto 1), el individuo “...de edad provecta, fisonomía benévola y estatura más que regular, vestido con ruana negra de paño, aforrada en tartán de cuadros que dejaba entrever bajo sus pliegues un saco-blusa de amotape azul; pantalones de tela de algodón, casi blanca y sombrero grande de paja, con ancha cinta en la cónica copa" que un día cualquiera atravesó el umbral que daba acceso a las habitaciones de Rivera y Garrido, amigo

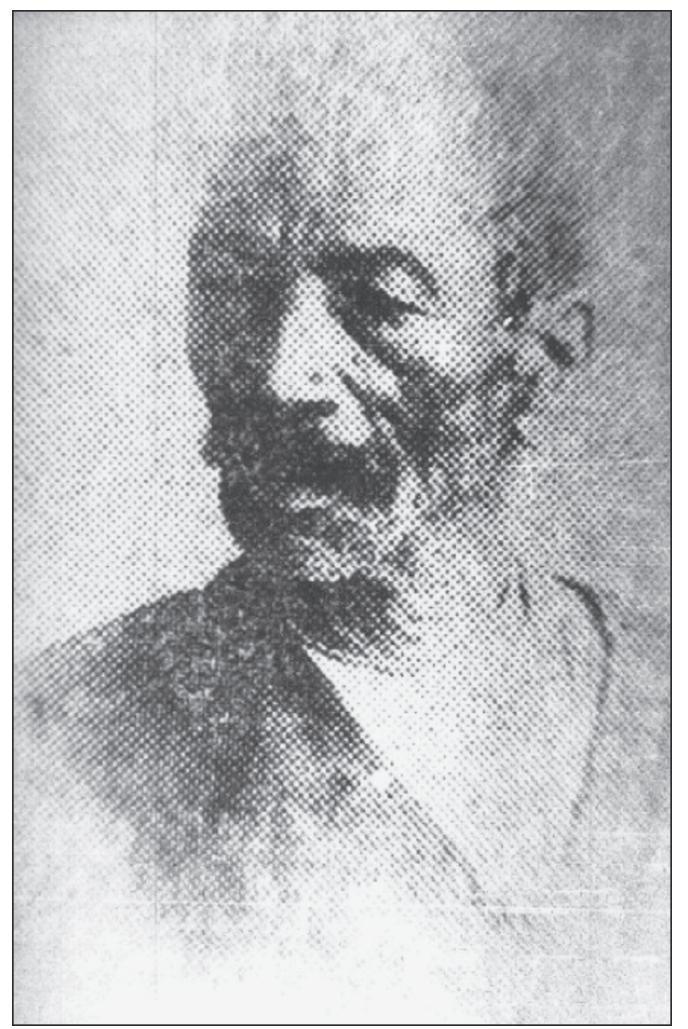

Foto 1. Juan Angel Molina (1830-1899). Fotografía tomada de El Tiempo, 18 de junio de 1967 (en: López 2002:253). íntimo de Isaacs, era según los parientes de este último, el mismo "negrito Juan Ángel” de la novela a quien los lectores recordarán como el paje de Efraín, el narrador y protagonista en la obra literaria (Isaacs: /1867/2001:56-71).

El supuesto hijo de Nay o Feliciana, princesa de un reino africano traída desde la provincia del Atrato a la hacienda La Rita por el padre del narrador en su último viaje a Jamaica, cobra vida desde un mundo transformado por la leyenda a través de las palabras que con orgullo dirige al amigo del novelista en ese año de 1897: "Mi madre se llamaba Isidora...Les contaba a las otras esclavas y sirvientas libres de la hacienda que ella había sido traída muy jovencita de por allá de los lados del mar, del país de Guinea, y agregaba que su padre era un gran jefe. Cuando las niñas del patrón Jorge bajaban a las haciendas del valle y mi madre veía las peineticas de oro que ellas se ponían a uno y otro lado de la cabeza para adornarse el cabello, me decía con tristeza: «Ve, Juan Ángel, de eso mismo era la corona que me ponían a mí en mi país, cuando mi padre daba alguna fiesta»" (ver: López, 2002: 252-253, 300). Nuestro personaje murió en la hacienda Pílamo de Caloto-Cauca el 14 de noviembre de 1899, con él, pudimos sacar a la luz a otros miembros del componente socio-cultural afrocolombiano vinculados a la tradición isaacsiana, antes ignorados por la investigación histórica; así, en el archivo de la catedral de Palmira reposan los nombres de Marcelina, Feliciana, Gregorio, Bruna, Remigio y Dolores entre otros, todos: "...esclavos del Sr. Jorge Isaacs" padre (ibid.).

Una impresión muy similar genera la figura humana estilizada en el panel del quilombo de Cabaça (Brasil), publicada por Guimarães y Lanna en 1980 (citados por Funari 1994a:40,43). Para los investigadores comprometidos con esos trabajos pioneros de la arqueología de las comunidades afro en América Latina, aquella representación pictórica, junto a los objetos recuperados en las excavaciones como vasos, botellas y pipas, demuestra la expresividad propia del mundo cimarrón, de un proceso creativo que busca afianzarse políticamente a través de redes de intercambio y contacto 
cultural, que constituyen el escenario donde las tradiciones ancestrales intentan ser más definidas, sin que esta afirmación implique que las controvertidas "huellas de africanía" representen el único criterio de análisis para entender el desarrollo e integración de los esclavizados africanos y sus descendientes con, un proyecto de construcción nacional que aún se debate en medio de la pobreza, el desplazamiento y el genocidio, tal como se deduce de los recientes sucesos en Bojayá-Chocó, donde sus habitantes fueron victimas de un conflicto que exhibe distintas máscaras en el panorama histórico colombiano (ver: Neira 2002); esto también incluye a las sociedades prehispánicas en disputa por el control de los valles interandinos y las altiplanicies. En su novela Andágueda, el escritor antioqueño Jesús Botero Restrepo realiza una excelente y pintoresca aproximación a este problema entre los mineros del Chocó durante la primera mitad del siglo XX:

_ ¡Eh, paisa! ¿Pol qué madrugó tanto, si se pué sabé? _ inquirió jovial desde la puerta y a guisa de saludo, un chocoano charolado, de tez de betún, abanicado la volátil ceniza de la mañana con el perfil abierto de la sonrisa mientras se amarraba a la cintura la amarilla coleta con parsimonia.

- iY a vos que te importa?

- Pejdone, pué, que di' habé sabío la repuejta, naa re había preguntao rezongó violento el negro, plegando para un mutis de la sonrisa el telón pulposo de los labios sobre la alba dentadura.

- Pues a mí no me jodás nunca negro pendejo.

- Mardita sea mi suejte que ujté lo que quié el bucame camorra y conmigo si tié que peliá.

Y palpó decidido con la mano de tizne, en la que resaltaba el pigmento canelo claro de la palma, el lugar de la peinilla en el cinto, quedando desolado al notarlo vacío.

(...)

Hubo revoloteo de filos en el gélido aire.

- No se meta nadie -sentenció una voz.
- Déjenlos que se maten. Pa eso son

hombres. (Botero Restrepo 1968?:25-26)

De una situación tan compleja, generada por el sometimiento, explotación y marginación de otros seres humanos por parte de grupos, instituciones y culturas dominantes, tenían que surgir los mecanismos que invisibilizan el papel de las minorías étnicas en la construcción de una sociedad moderna y esencialmente mestiza que, por cierto, no acabamos de entender. Es precisamente ahí donde radica la importancia de la arqueología como recurso científico que aporta elementos de discusión a la dinámica social como fundamento de identidades personales, grupales, regionales, étnicas y básicamente territoriales. En su disertación sobre la enseñanza de la historia nacional, publicada inicialmente en el periódico El Tiempo de Bogotá el 20 de noviembre de 1977, el historiador y filósofo Néstor Emilio Mosquera afirmaba lo siguiente: "El temor es fundado: la historia es un enorme recipiente donde las clases sociales y los pueblos tienen depositados sus intereses pasados y futuros. Nunca la mirada de la historia es indiferente. Esa es la razón de todo Estado por hacerla oficial. (...) Entonces, el primer problema que ofrece la historia es que el pueblo la hace pero le enseñan otra" (2003:36)

Más que definir la problemática afro desde una visión particularizada, el desarrollo de nuestro artículo busca entender la articulación y transformación de ese componente en un modelo social donde interactúan distintas maneras de ver el mundo subordinadas a los grandes proyectos colonialistas, imperialistas y oligárquicos como factor determinante, aunque estas últimas designaciones no siempre hagan presencia en la historiografía colombiana, y mucho menos en la bibliografía arqueológica. Funari (1993:21; 1995:242-243), por ejemplo, entiende la aparición de los nuevos modelos teóricos en la historia de la arqueología brasilera desde una tendencia académica de carácter humanista, exiliada por un régimen militar que, entre 1964 y 1985, apoya proyectos extranjeros que reducen el interés por la identificación de esas contradicciones y luchas de 
clase en el registro arqueológico y archivístico a favor de actividades descriptivas que, según el autor, proponen una "ciencia neutra" donde el arqueólogo termina asumiendo una postura apolítica. En el modelo tradicional clasista de la sociedad brasilera, los programas educativos y la apropiación cultural del patrimonio histórico son utilizados como mecanismos que suprimen, enmascaran, invisibilizan y refuerzan en la mentalidad popular un imaginario de influencia europea que apoyándose en el mito de los bandeirantes, justifica la exclusión e inigualdad de indígenas y afros como gestores sociales y copartícipes de la nacionalidad (Funari 1993:20-27; 1994b).

El mismo carácter poseen las exposiciones permanentes en el Museo Nacional de Colombia donde, a pesar de algunas modestas innovaciones que apuntan a destacar el componente afro en el desarrollo histórico de este país, especialmente con el tema de Domingo "Benkos" Bioho y el cimarronismo en la Costa Caribe, lo que sin duda resalta de una manera sustancial es el poder simbólico que aún ejercen las figuras pictóricas y objetos cotidianos de próceres y presidentes de la República. Sin dejar de reconocer el impacto que esos representantes de la elite han tenido sobre nuestras vidas, lo cierto es que la invisibilidad de aquellos que trabajaron las minas y grandes haciendas neogranadinas propiciando los alcances tecnológicos y los grandes capitales que hacen de Colombia una nación a punto de ser definitivamente integrada, parece, al nuevo orden mundial, lo son por haber hecho parte de grupos subalternos que no tenían en la escritura el principal medio para comunicarse y fortalecer una memoria que se diluye en la oralidad y, los vestigios materiales que hacen presencia al margen de lozas y porcelanas importadas en sitios arqueológicos que la selva, la montaña y la sabana han ocultado (o protegido) a la memoria oficial. Esto es lo que da importancia a la opinión de Funari:

Si el pueblo poco aparece en los documentos escritos, si cuando aparece no pasa de citación de la elite, si para llegarnos a él la fuente es antes un obstáculo que un camino, esta misma masa anónima domina el documento material: la cultura material es producto directo del pueblo. (...) Estos y otros deseos de los esclavos, muy raramente presentes en fuentes escritas, están presentes en instrumentos musicales, en juguetes, en botellas y muchas otras cosas más, hechas o usadas por los esclavos mismos cuyos restos constituyen el material principal de la arqueología histórica (1994a:36)

A pesar de todo, no cabe aquí el concepto de "etnoarqueología" en el amplio sentido de la palabra, exceptuando el valor que su método de confrontación y analogía etnográfica pueda tener en un momento dado, ya que como se insiste arriba, es más importante abordar el estudio de aquella matriz histórica como una problemática integral en un contexto multifacético donde intervienen varios grupos que se influyen mutuamente, y que en el plano del mestizaje, dan lugar a enmascaramientos, sincretismos y/o yuxtaposiciones. Aún así, al iniciar el reconocimiento arqueológico de Nóvita Viejo el 4 de enero de 2003, éramos conscientes de que, quizá, los vestigios coloniales y republicanos que nos permitirían hacer aportes a una arqueología tan deficiente en investigaciones consolidadas podrían tornarse "invisibles" ante nuestra capacidad teórica e interpretativa debido a las múltiples variables que caracterizan este fenómeno de contacto y resistencia cultural; una de ellas expresa la necesidad de distinguir la producción material de los esclavizados de este Real de Minas de la de otros actores: esclavistas, indígenas y "mestizos" que de una manera u otra, estuvieron involucrados con la explotación de oro y

(2) Antes que recurrir a una clasificación antropométrica, el término mestizo es utilizado aquí desde una perspectiva histórica para hacer referencia a individuos que entran en escena como producto de relaciones genéticas y culturales entre aquellos troncos: el esclavizado traído de Africa, el europeo y el indígena americano. Así por ejemplo, el informe sobre las provincias del Chocó que el capitán de ingenieros Juan Jiménez Donoso dirige a las autoridades españolas en 1780, hace distinciones entre libres y esclavos de "varios colores" (folio 7v). 
platino en ese lugar durante casi todo el siglo XVIII y la primera mitad del siguiente.

Dicho problema es común a todos los informes sobre "Arqueología Afroamericana" desde que Charles H. Fairbanks adelantase los primeros estudios en sitios de la costa este de los Estados Unidos (Georgia y Carolina del Sur) durante la década de los sesenta. Con estas primeras excavaciones, realizadas en asentamientos de una población negra que veía "aislada" en el contexto general de las haciendas algodoneras de la colonia británica, Fairbanks se mostraba más interesado en la identificación de una alfarería típica afro-americana que en el reconocimiento de "huellas de africanía"; es decir, en la búsqueda de patrones o rasgos culturales de origen africano que hubiesen sobrevivido a los procesos de aculturación, explotación y sometimiento, y que, de alguna manera, se vieran reflejados en esos objetos materiales (Singleton 1988:346-347). Esta misma discusión ha ganado vigencia en nuestro país con planteamientos de orden etnohistórico y etnográfico defendidos por investigadores como Aquiles Escalante, Nina S. de Friedemann, Jaime Arocha, Adriana Maya y, específicamente, por Armin Schwegler en su aproximación arqueológica al cementerio de San Basilio de Palenque-Bolivar, comunidad en la que afirma distinguir pautas funerarias de origen congoangolés (1991). ${ }^{3}$

En Norteamérica, la controversia en torno a la producción cultural afro se acentúa cuando, en 1962, Noël Hume clasificó una cerámica que mezclaba características europeas y no-europeas a la cual llamó inicialmente Colono-Indian-Ware, por considerarla de origen nativo con influencia foránea. Al tiempo que

(3) Señala por ejemplo la costumbre de enterrar a los muertos con objetos personales como ropa, tenedores y esteras; de la misma forma: cementerios a la entrada o salida de los poblados y tumbas protegidas por techos, al tiempo que no es clara la versión palenquera del "culto del niombo" o tipo de momificación practicada por grupos africanos. La discusión empieza cuando nos vemos obligados a reconocer que esas manifestaciones culturales también hacen presencia en otras sociedades del mundo, entre ellas la indígena americana y la europea.
Steven Baker, una década después, relacionaba esos vestigios con los indígenas catawbas de Carolina del Sur, se estaba excluyendo a los afroamericanos como posibles autores o copartícipes de las manifestaciones artísticas que se integran a esa producción alfarera. La presencia de esos objetos en los sitios de esclavitud sería entonces explicada por simple intercambio comercial (Funari 1996:4-5). En situaciones como ésta, es donde parece evidenciarse con nitidez el rol político que las interpretaciones arqueológicas juegan como parte de valoraciones que reviven los mecanismos de estigmatización social, de ahí que sea un tanto cuestionable la propuesta de que el arqueólogo que no asume una posición vanguardista es necesariamente apolítico, ya que sin duda, las clasificaciones tipológicas y las rigurosas descripciones constituyen un poderoso instrumento de exclusión a favor de otra perspectiva dominante. Por esa misma ruta es como se ha llegado a considerar que las obras de Picasso, Botero y Dalí son arte mientras las representaciones pictóricas callejeras en los ámbitos rural y urbano son "artesanías". Otro planteamiento muy conocido es el que cataloga como escritura a los textos epigráficos de Roma, Egipto y Fenicia, y como "ideogramas" a los signos pintados y tallados de origen indígena y afro que se extienden por diversas regiones de Sudamérica y las Antillas; aunque de manera paradójica, el mismo concepto de "arte rupestre" ya genera una actitud conformista que limita nuestro acercamiento a la complejidad de esos significados.

Ignorando por un momento las valiosas obras artísticas elaboradas en las antiguas ciudades de los reinos de Ghana, Mali y Benin del occidente de África, entre los siglos VIII y XIV (ver algunos ejemplos en: Consejo Nacional de la Cultura 1993), habría que atribuir ese aparente vacío en la producción material de los esclavizados en las haciendas de New England, como se desprende de las interpretaciones de los primeros arqueólogos que abordaron el tema, a un desajuste teórico que comenzó a ser replanteado por Leland Ferguson (1992; citado por Funari 1996:5 y Singleton 1988:348-349) en lo que hace referencia a la 
cerámica que entonces pasó a llamarse Colonoware. Desde su óptica, este autor concluye que dicha alfarería es la representación simultánea de las tradiciones catawba y afroamericana; en otras palabras, que corresponde a un conjunto de objetos cerámicos producidos y usados tanto por indígenas como por afros.

Para Martín Hall (citado por Funari 1996), la existencia de esos recipientes domésticos en los sitios arqueológicos expresa un fenómeno muy importante de resistencia cultural cuyo propósito, más que exhibir tradiciones indígenas y africanas, denota una polarización social "no-europea" frente a los opresores. Con todo eso, y de manera específica para el componte afro, Ferguson cree distinguir recursos técnicos en la producción alfarera y una serie de representaciones simbólicas que, eventualmente, podrían atribuirse a influencias afro-caribeñas antes que a un sustento cultural "directamente" importado desde África (1992), pues entre otras cosas, las nuevas investigaciones facilitan concluir que la variedad en la distribución de estos artefactos sobre las plantaciones de la costa este de los Estados Unidos, estaría evidenciando respuestas adaptativas de los afroamericanos a los presiones sociales generadas durante un lapso de ciento cuarenta años que se entienden de acuerdo a tres periodos: Esclavitud Colonial (1740-1790), Propagación de la Esclavitud (1790-1861) y, Guerra Civil y Abolición (1862-1880).

Irónicamente, al ser abolida la esclavitud, estas poblaciones se vieron obligadas a responder a nuevas circunstancias de orden político y económico que transformaron sustancialmente aquellos reductos de "herencia africana" (Singleton 1988:345-346). En 1988, como parte del Proyecto Annapolis, se efectuaron excavaciones arqueológicas en tres sitios correspondientes a ocupaciones afroamericanas de comunidades libres y de esclavizados. ${ }^{4} \mathrm{La}$ recuperación y análisis de material cerámico,

(4) No sería descartable efectuar una profundización teórica acerca de la pertinencia o no del concepto de "comunidad" para referirse a las poblaciones afro que subsisten bajo el régimen de la esclavitud. botellas de cristal y restos de comida si bien demuestran la continuidad de prácticas culturales de origen africano, también permiten hacer evidente la inevitable absorción de esos rasgos por parte de la ideología dominante a través del uso de medicamentos y bebidas alcohólicas, que coexisten en medio de pautas de resistencia cultural basadas en el consumo alimenticio de ranas obtenidas fuera del mercado (Mansilla 2000:9-10; citando a Leone et.al. 1995).

De esa manera, cualquier aproximación arqueológica a las comunidades afrocolombianas debería partir de un entendimiento profuso de las diferencias regionales en cada momento decisivo de la historia nacional (López 1993). Ahora bien, desde la perspectiva afro, esos cambios o continuidades podrían ser evidentes con la oportuna interpretación y difusión pedagógica de tradiciones orales, ritos y creencias, los cuales, nos facilitan entender procesos que finalmente son de naturaleza transcultural. El antropólogo y co-investigador John Antón Sánchez, nativo del Municipio de CondotoChocó afirma lo siguiente: "Independiente del modelo arqueológico que se asuma para diseñar una especialidad para las comunidades negras, se piensa que este debe buscar la reconstrucción histórica del pueblo afrocolombiano, teniendo en cuenta todas sus referencias culturales como la tradición oral, el mito, el arte, el folklore, además de los aportes de las fuentes primarias" (2002:4).

La afirmación de la transculturalidad se puede entender no sólo con los múltiples vocablos de origen africano extendidos en las diversas regiones de Colombia tales como bunde, mondongo y bambuco (ver: Escalante 1964:145-182; Pereachalá en: Anónimo 2003), sino también con las tradiciones que, por ejemplo, aún conserva doña Esther Mosquera de la comunidad de San Pablo Adentro en Itsmina-Chocó (Foto 2), a propósito de una leyenda sobre "tres cruces" que se iban erigiendo en el poblado para eludir la influencia maligna de un ser de apariencia caucásica (Entrevista. 6 de enero de 2003). Según Escalante, las técnicas de explotación minera, tan conocidas y diversificadas ahora en la 


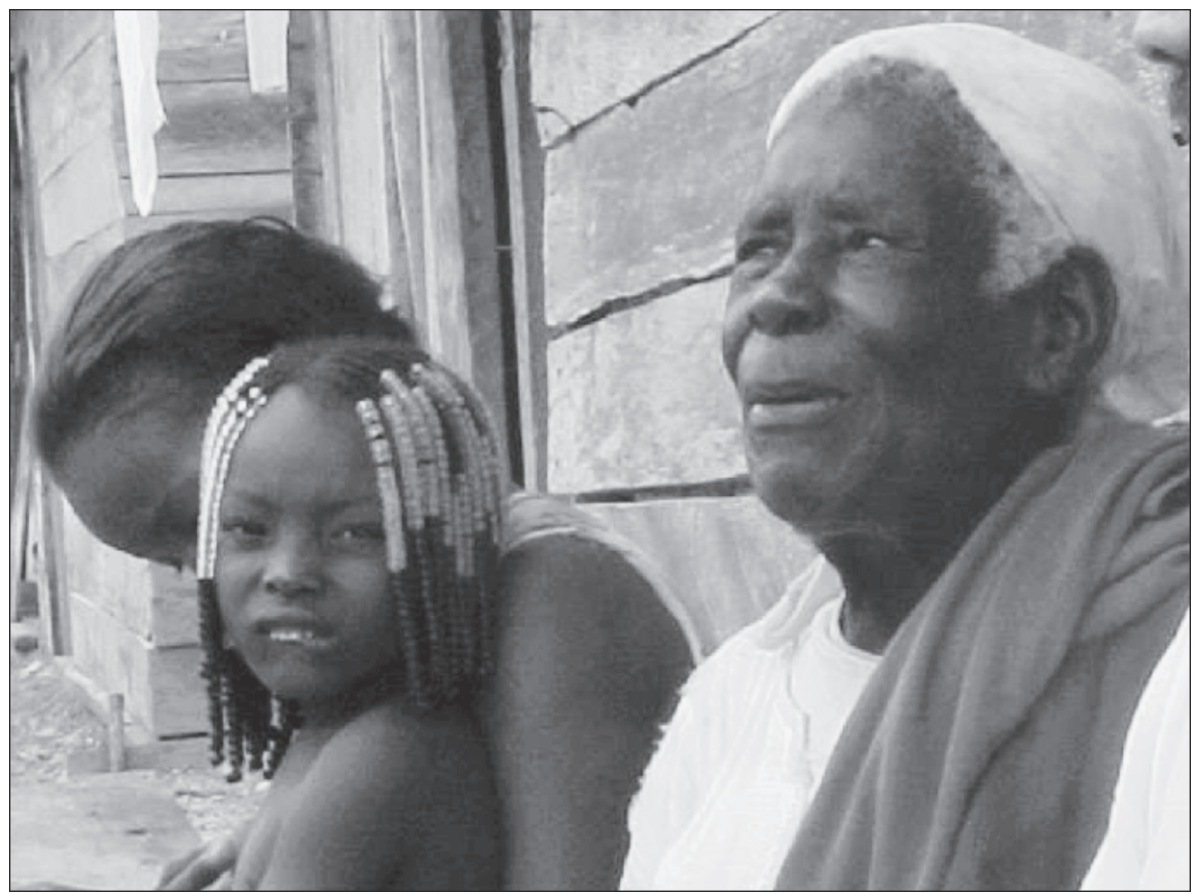

Foto 2. Esther Mosquera narrando una leyenda local (San Pablo Adentro-Itsmina).

Costa Pacífica, tienen su precedente en los sistemas utilizados por los indígenas desde antes de la Conquista para la obtención del material aurífero en depósitos aluviales; más tarde, fueron adoptados por españoles y afros en los reales de minas (1971:78). En términos metodológicos, es importante señalar cómo la integración de fuentes orales, documentos de archivo y toponímicos que aluden al quilombo de Ambrosio (Minas Gerais-Brasil), destruido por un incendio en 1746, han sido de absoluto valor para distinguir filiaciones que Mansilla (2000:11) denomina "etnoculturales", al tiempo que permiten establecer diferencias entre asentamientos de tipo agrícola y minero como expresión de un fenómeno de naturaleza americana que, a pesar de las particularidades, nos corresponde valorar analógicamente debido a sus semejanzas con el caso colombiano.

En el terreno de lo que muchos autores denominan: "cultura material", los análisis de tecnología cerámica efectuados por Petersen y Watters (1988) con veinte fragmentos correspondientes a ocho vasijas, hallados en asociación con tumbas utilizadas para sepultar los cuerpos de diez individuos en el cementerio colonial de Harney (Montserrat, Indias Occidentales), comparten técnicas de manufactura, cocción y tratamiento de la superficie que permiten distinguirlos de la cerámica nativa, a pesar de las dificultades que implica afirmar si esos objetos fueron elaborados localmente para definir una vinculación con actividades de consumo. La evidencia de patologías en los restos óseos como osteoartritis, anemia y desnutrición, así como una alta incidencia de fracturas, hace pensar a los arqueólogos que se trata efectivamente de esclavos inhumados allí a finales del siglo XVIII (Petersen y Watters 1988:169-170).

En ese sentido, la búsqueda de una alfarería "afroamericana" es muy similar a la búsqueda de "huellas de africanía" en otros rasgos culturales. Una buena parte de la generación de los setenta recordará con nostalgia a Kunta Kinte, el protagonista de la novela Raices de Alex Haley, en su infructuoso y desesperado intento por huir de la plantación Waller y atravesar el océano para regresar a su Gambia nativa tras la memoria de sus padres 
Omoro y Binta. La admiración y respeto que inspiraba aquel héroe en un público ansioso por el éxito de su audaz empresa, no pudo evitar que en la serie de televisión, y en la vida real, sus descendientes se transformaran en una familia norteamericana que doscientos años después se preguntaba acerca del significado de palabras como "Kamby bolongo" y "ko", supuestamente pronunciadas por "Toby": el nombre impuesto por el esclavista para ocultar la verdadera identidad de Kinte, según la tradición oral de la prima Georgia: "i...y estaba cortando madera para hacer un tambor cuando lo robaron!" (Haley /1976/1978:570-594).

Ignorar los procesos de adaptación y transculturación que en nuestro continente siguen al ingreso de personas oriundas de grupos étnicos de la costa occidental y el norte de Africa, puede conducir inconscientemente a un determinismo genético enmascarado por clasificaciones estilísticas, es decir, a una actitud racista y segmentada donde el hecho de ser "negro" implica generar una alfarería típica que distingue a esos grupos de los demás, lo cual ubica nuestra problemática al margen de un enfoque integral en antropología, pues los afroamericanos habrían sido totalmente capaces de elaborar objetos de vidrio, loza o porcelana si las circunstancias así lo hubiesen exigido, aunque a decir verdad, el término "afro" no se desprende mucho de una connotación discriminante, así haya sido gestado por los círculos académicos y las mismas "negritudes".

A propósito de la transculturación, las implicaciones que este fenómeno tiene con relación al problema del etnónimo o la búsqueda de un término construido desde una perspectiva émica, es decir, por los mismas comunidades americanas que se reconocen "afrodescendientes" (ver: Pereachalá 2003), se acentúan con el relato que Whitten y Friedemann (1974:95-96) retoman del viajero y sacerdote Miguel Cabello Balboa para señalar cómo, a finales del siglo XVI, un grupo de veintitrés africanos provenientes de Guinea se fugó de una embarcación liderado por el ladino Alonso de Illescas, con quien se internaron en la provincia de Esmeraldas (Ecuador). Allí entraron en contacto con los indígenas, y tiempo después, cuando las autoridades de Quito negociaban su sometimiento a la Corona Española, ya se hablaba de una "República de zambos" cuyos miembros, según lo representa una pintura de la época, aparecían vestidos con trajes europeos y adornados con narigueras, orejeras, collares y pectorales según el estilo indígena de la región.

La Rosa Corzo (1996), por su parte, analiza un conjunto de esculturas zoomorfas y antropomorfas, así como algunos petroglifos hallados en 1938 en el interior de una cueva durante un reconocimiento petrolífero en la zona NW de la Ceiba del Agua (Provincia de La Habana), como un emplazamiento de culto afrocubano que posiblemente se relaciona con una entidad creadora de origen yoruba denominada Olórum, lo cual sería evidente debido a la presencia de figuras solares y cruces encima de rostros humanos como parte de esa simbología. No obstante, citando la superposición de esos mismos elementos sobre pictografías indígenas en la zona de Matanzas, el autor no descarta la eventual influencia de tradiciones míticas antillanas sobre grupos de cimarrones, que en el siglo XIX habrían reutilizado este sitio para sus ceremonias: "Es bueno aclarar que bajo estos criterios no se pretende introducir una carta que separe de manera radical las manifestaciones del arte rupestre aborigen de las de posible filiación africana", concluye (ibid.:50).

De todas formas, parecería que la discusión sobre el etnónimo por parte del movimiento afrocolombiano lleva consigo la dificultad (o ventaja) que implica el uso de términos particularizantes que, bajo la óptica regional, derivarían fácilmente en clasificaciones como "afrosanjuaneño”, "afroatrateño”, "afrosanandresano" o "afrocaleño", vocablos que todavía no son de fácil asimilación por parte de las personas que en este mismo instante, fuera de los círculos políticos y académicos, laboran en las minas bajo un sol ardiente o son víctimas de la prostitución, el hambre y la violencia en las grandes urbes. ¿Cómo interpretarán los arqueólogos del futuro nuestras observaciones, los informes periodísticos y las estadísticas oficiales?. Es más fácil entender las razones de Funari cuando propone una arqueología humanista de corte sudamericano 
que, haga frente a la Globalización a través de campañas pedagógicas que fomenten la autocrítica y el discernimiento frente a las desigualdades sociales: "A Educaçao significa muito mais do que a transferência da cultura da elite para as massas (Brandão 1984:18), significa a construção da cultura do povo através da compreensão da cultura popular cotidiana. Superando a educação reproductiva e imitativa, preocupada somente com a submissão social e intelectual do educando" (1993:19).

Más que referirse a una producción material sincrética, se debería explorar el significado que esta tuvo a nivel histórico como respuesta adaptativa a las presiones sociales. No se trataría de distinguir un conjunto de características para un grupo étnico, sino, el conjunto de características que expresan el cambio como producto de respuestas culturales de ese grupo étnico en un espacio y tiempo determinados. Así por ejemplo, cabría preguntarse: ¿Qué efectos tuvo la abolición de la esclavitud en la Nueva Granada (1852) sobre las manifestaciones artísticas de los grupos afro que residían en las haciendas y caseríos próximos al río Amaime (Valle)?. ¿Estamos en capacidad de percibir esos cambios en la alfarería y/o la metalurgia?. Para Stemper y Salgado (1993a:85-86), dos objetos con apariencia floral elaborados en oro y cobre que fueron descubiertos en el asentamiento de Tatabrito (Bajo San Juan), se relacionan con un complejo artesanal afrocolombiano extendido por toda la Costa Pacífica al que preceden estilos y técnicas de aleación de origen prehispánico. Los adornos, cuya edad sobrepasaría los cien años, se atribuyen a los mismos grupos que ayudaron a construir trochas y comparten tradiciones sobre caminos empedrados y lugares de enterramiento con indígenas waunanas (1993b:283). Particularmente, y reiterando aquello de las diferencias en el contexto regional y socio-cultural, observamos cómo en Jamaica el Code Noir (Código Negro) permitió a los esclavizados introducir en el sector mercantil objetos de alfarería de su propia manufactura, la cerámica utilitaria de terracota denominada yabba (Therrien, Uprimmy, Lobo G., Salamanca, Gaitán y Fandiño 2002:40, citando a Meyers 1999).
Sobra advertir la importancia que para esta discusión posee el trabajo de Jimena Lobo Guerrero en la población de Gachantivá Viejo (2001), pues con ayuda del material recolectado y la documentación de archivo, desafía el inexplicable silencio o la aparente indiferencia de la arqueología colombiana a los fenómenos de contacto. Dicho estudio se apoya en las tesis defendidas oportunamente por Mónika Therrien de la Universidad de los Andes, en torno a la persistencia de tradiciones alfareras en el altiplano cundiboyacense durante el periodo colonial (1991). Hasta ahora toda la cerámica de apariencia "burda" era considerada "prehispánica", aunque esta hubiese surgido de las manos del alfarero muisca en 1546 , siete u ocho años después de la fundación de Santafé de Bogotá. Una brecha que también nos hace conscientes de los obstáculos por superar en el camino hacia una arqueología afrocolombiana, ya que genera el mismo interrogante que dio continuidad a las investigaciones norteamericanas en la década de los sesenta: ¿Acaso no hubo producción cultural por parte de los grupos afro?: "Aunque la influencia es muy sutil, este estudio y los que lo preceden plantean que también estos grupos incidieron en la manufactura alfarera e imprimieron sus propios códigos no sólo en las vasijas que utilizaban, sino también en las que conformaban el menaje doméstico de grupos culturales más amplios" (Therrien et al. 2002:40).

El rapto de Lucía Angola por parte de cimarrones del palenque de la Magdalena (Costa Caribe), por ejemplo, introduce una descripción basada en la consulta archivística que ubica a los esclavizados en el contexto de la "cultura material", sin que esa fuente los señale en forma directa como responsables de la producción de objetos cotidianos: "De esa forma fue tomada por sorpresa Lucía Angola, en una oportunidad que salió fuera de la calle de la Media Luna a un tejar a buscar cazuelas, ollas de barro y a recoger ceniza" (Navarrete 2003:140). Sin embargo, las investigaciones adelantadas por la historiadora de la Universidad del Valle, demuestran que la vida al interior de la sociedad palenquera estaba asociada a un interesante desarrollo arquitectónico con 
habitaciones o chozas de madera, caña, palma y bejuco, rodeadas de fosos cuajados de púas venenosas, así como "ramadas" destinadas a la sepultura de los muertos (ibid::142-143).

El Proyecto Arqueológico de Palmares (Brasil), desarrollado por iniciativa de los profesores Charles E. Orser de The Illinois State University y Pedro Paulo Funari de la Universidade Estadual de Campinas entre 1992 y 1993, ha marcado un hito en el estudio de esta temática en Sudamérica debido a que facilita un entendimiento ampliamente caracterizado en torno a los procesos de adaptación, transculturación y resistencia de una comunidad de cimarrones surgida en 1605 en la Serranía da Barrigas. A pesar de los frecuentes incursiones de tropas holandesas y portuguesas que buscaban recuperar el control, este quilombo ${ }^{5}$ supo mantener su autonomía política durante un lapso de ochenta y nueve años hasta su derrota en 1694. En realidad, el término "Palmares" designa una "región concreta" de $140 \mathrm{~km}$. de largo que incluye las estribaciones montañosas extendidas paralelamente a la zona costera en los estados de Alagoa y Pernambuco, área geográfica en la que se estudiaron catorce yacimientos arqueológicos asociados a la presencia y actividad de estos quilombos durante casi todo el siglo XVII. Las investigaciones arrojaron un número considerable de objetos (alrededor de 2500) entre los cuales se destacan dos tipos de alfarería comunes a todos los yacimientos excavados: una cerámica gruesa sin decorar de superficie rojiza y otra fina de características

(5) El término Ki-lombo se origina de la palabra angolesa ovimbundu, que en lengua kimbundu significa "casa" o "agrupación de hombres guerreros con fines rituales" (Mansilla 2000:13). Para Funari (citado ibid.), esa primera designación terminó adquiriendo connotaciones negativas a pesar de que durante el siglo XVII, los propios ocupantes de Palmares, esclavizados que huían de las plantaciones de la costa nordeste del Brasil, denominaban Angola Janga (Pequeña Angola) a ese conjunto de asentamientos; posible relación ancestral de los rebeldes con el occidente de Africa. Los quilombos son la versión brasilera de nuestros famosos palenques de las costas atlántica y pacífica, y uno que otro en el interior del país. semejantes pero obtenida bajo una temperatura de cocción de baja a media. A esto se adiciona un recipiente para almacenar grano que contenía dos hachas de piedra y fragmentos de cerámica.

Se destaca la presencia de cuatro pipas, dos de las cuales estaban decoradas con "palmeras", lo que sugiere una posible alusión simbólica a la resistencia inspirada en lo que en su momento se denominó "República de Palmares". El modelo interpretativo abordado desde el enfoque mutualista de Orser, la teoría del mosaico cultural de Allen y la perspectiva de clase de Rowlands (citados por Mansilla 2000:14) se apoya en la definición arqueológica de una estructura social multi-étnica en esta comunidad, lo cual halla eco con la presencia simultánea en el Sitio 3 de cerámica indígena tupinambá, europea de posible origen holandés y otra señalada como "Palmarina" cuya filiación cultural, antes que revivir el paradigma reduccionista de la alfarería Colonoware, debe entenderse como expresión material de una sociedad pluralista caracterizada por la creación de nuevas formas estéticas, y no como simple reproducción de tradiciones africanas, indígenas o europeas pre-coloniales, afirma Funari (1996:5). En territorio colombiano, una mirada arqueológica a los palenques de la Costa Caribe, podría definir alguna concordancia con la imagen que María Cristina Navarrete tiene de esas sociedades cimarronas, donde las relaciones de parentesco afianzadas en la matrifocalidad y la poligamia dan lugar a un "conglomerado étnico de construcciones culturales y sociales diversas” (2003:136).

Esa visión integral del contexto arqueológico de Palmares facilita deducir las interacciones dadas a través del comercio de frutos, objetos de metal y armas de fuego entre enemigos naturales, incluidos algunos colonos que teniendo poco que perder y poco que ganar, les resultaba más ventajoso económicamente colaborar con los fugitivos (ibid::7), de ahí que para Mansilla: "Las relaciones entre africanos, nativos y europeos sólo pueden entenderse en el marco de un mundo marcado por el colonialismo, el eurocentrismo, el capitalismo y la modernidad interactuando a nivel particular y global" 
(2000:15). Sin embargo, desde la perspectiva contemporánea, los medios de comunicación brasileros facilitaron que la opinión pública se viese polarizada entre quienes defendían los resultados arqueológicos como evidencia de una sociedad abierta y heterogénea frente al opresor y, aquellos que perfilaban la imagen de una comunidad cimarrona "no muy africana" que reproducía la explotación colonial al interior de su propio territorio; mientras tanto, las investigaciones revelaban los vínculos de los palmarinos con estrategias culturales que integraban el culto a la Virgen María con el "respeto sagrado" a sus líderes.

De todas formas, el impacto social de esta labor científica manifiesta una alianza con las comunidades locales y un movimiento afrobrasilero que (Funari 1994a), le ha otorgado vigencia a la memoria de un nuevo héroe nacional: Nzumbi, "...la primera gran figura negra del Brasil”, cuya muerte, sobre la de aquellos que lo acompañaron en la resistencia cimarrona de Palmares, es conmemorada el 20 de noviembre: "Día de la Conciencia Negra”. Su monumento, cual héroe extraído de las páginas de Carlyle, se yergue sobre una colina ubicada a ocho kilómetros de una moderna ciudad que paradójicamente, a raíz de los festivales inaugurativos de 1982, habilitó allí una pequeña carretera que buscando facilitar el acceso a los turistas destruyó una buena parte de los sitios arqueológicos antes de que se iniciasen las prospecciones de Orser y Funari (ibid.: 14, 17-20).

Por último, en el contexto de todo lo que hemos señalado, queda referirse a las aproximaciones arqueológicas que a principios de enero de 2003 realizamos en el sitio que la tradición del Alto San Juan (Chocó-Colombia) denomina "Nóvita Viejo", haciendo referencia a un yacimiento ubicado a casi kilómetro y medio de la cabecera del actual municipio, el cual hizo parte de un reconocimiento general que involucró otros lugares de la región como San Pablo Adentro y el Canal del Cura (Municipio de Itsmina), que a pesar de seguir vigentes en la memoria de estas poblaciones ribereñas, corren el riesgo de desaparecer por efecto negativo de la industria minera sobre el medio ambiente y los imaginarios sociales, que dinamizan la enorme riqueza cultural de este departamento ubicado en el occidente del país; a esto se suman inconvenientes en el orden público motivados por la presencia de grupos armados que impiden acceder a los sitios arqueológicos.

En el marco de las investigaciones pioneras sobre lo que muchos especialistas optan por llamar "arqueología afrocolombiana", este trabajo va antecedido por estudios influyentes en el campo de la etnografía, la etnohistoria y la etnolingüística que a la fecha deberían ser incorporados a un "modelo integral" cuya aplicación puede servir de base para futuros estudios; con esto, se quiere enfatizar en la importancia que tienen los resultados obtenidos como producto de la correlación de fuentes primarias y secundarias que, aparte de una extensa historiografía, comprenden la tradición oral, los documentos de archivo, el registro etnográfico, la iconografía y los recursos visuales y sonoros como fotografías, mapas y grabaciones obtenidas en campo. Teniendo como punto de partida la definición y propuesta de esa problemática antropológica por parte de las mismas comunidades involucradas, se hace también necesario un compromiso retributivo de tipo pedagógico representado por informes, talleres, conferencias y publicaciones que involucren a esos grupos étnicos con sus propias intereses sociales, políticos, económicos y religiosos, facilitando una aproximación entre el antropólogo y el trabajador social como un hecho inevitable en el futuro de la disciplina.

Nuestra labor se había iniciado realmente en la década de los noventa como estudiantes del Departamento de Antropología de la Universidad de Colombia; allí, la idea surgió como respuesta a las discusiones sostenidas en los cursos de arqueología, etnología y etnohistoria coordinados por los profesores Gerardo Ardila, Jaime Arocha y Adriana Maya respectivamente, en el sentido de definir los alcances y limitaciones que tendría un proyecto arqueológico sobre las comunidades afrocolombianas. Poco antes de haber llegado a mis manos una copia mimeografiada del informe de Armin Schwegler sobre San Basilio 
de Palenque titulado: "Hacia una arqueología afrocolombiana: restos de tradiciones religiosas bantúes en una comunidad negroamericana" (1991), y de haber tenido conocimiento de la propuesta que Angélica M. Suaza (1995) estaba desarrollando con la misma población de la Costa Caribe, se había defendido una ponencia sobre esta temática en Popayán durante el III Encuentro de Estudiantes de Antropología (López 1993).

Tiempo después, con un grupo estudiantil interesado en la arqueología histórica, y por expresa recomendación de la profesora Mónika Therrien de la Universidad de los Andes, se gestionó la obtención de material bibliográfico que oportunamente nos hizo llegar la Dra. Betty Meggers del Smithsonian Institution (Washington D.C.) y el Dr. Pedro Paulo Funari de la Universidade Estadual de Campinas (São Paulo-Brasil). Con ello, y el fuerte interés que el antropólogo John Antón Sánchez puso entonces en el desarrollo de una arqueología para su comunidad, fue posible diseñar una propuesta metodológica inspirada en algunos informes extranjeros sobre arqueología afroamericana, que coincidió con la publicación de una columna del periódico La prensa del San Juan de Condoto-Chocó en el cual Antón cumplía funciones periodísticas, donde se clamaba por la urgencia de un rescate histórico y arqueológico para el antiguo "Real de Minas de Soledad del Tajuato" [San Juan del Tajuato en: Escalante 1964:75], cuyas evidencias se hallaban próximas a un caserío que aún conservaba objetos religiosos de la capilla colonial (Mandinga 1997:7). Nuestro proyecto debió esperar hasta mediados de octubre de 2002, cuando el seminario: "Arqueología Histórica: una mirada hacia nosotros mismos", programado en la ciudad de Cali por el Área Cultural del Banco de la República, y que contó con la participación de los arqueólogos Felipe Gaitán y Jimena Lobo Guerrero, propició la invitación recibida de parte del Municipio de Condoto y la Fundación Las Mojarras de la misma localidad, para llevar a cabo un reconocimiento arqueológico en el sitio que marcaba la ubicación de lo que otrora fue la capital de la Provincia del San Juan y uno de los emporios mineros de mayor prestigio durante la transición política que va desde finales de la Colonia hasta el comienzo de la República de la Nueva Granada:

Nóvita es la madre del Chocó negro, el epicentro desde donde salió a desperdigarse por el territorio el mayor número de familias que llevaban en su equipaje la marca de cientos de años de esclavitud y que heredaron el apellido de sus amos: Palacios, Moreno, Perea, Caicedo, Hurtado, Mosquera, entre otros...la importancia que tuvo hasta mediados del siglo XIX está reflejada en que su nombre figure en los principales mapas, después la decadencia trajo tal olvido que hasta los mapas la olvidaron (González 1997:11).

El área de estudio hace parte del Municipio de Nóvita, el cual se encuentra ubicado a $4^{\circ}$ $57^{\prime}$ de latitud norte y $76^{\circ} 36^{\prime}$ de longitud oeste del meridiano de Greenwich, con una superficie que alcanza los $1.148 \mathrm{~km}^{2}$; mientras la cabecera (Foto 3), a $70 \mathrm{~m}$ de altura sobre el nivel del mar, se halla emplazada en la margen izquierda del Río Tamaná, el principal afluente de esta zona que se extiende en sentido E-W desde su nacimiento en el cerro del mismo nombre a una altitud de $1.600 \mathrm{~m}$ sobre la Cordillera Occidental, hasta su desembocadura en la cuenca del San Juan. Posee una temperatura media de $28^{\circ} \mathrm{C}\left(16^{\circ} \mathrm{C}\right.$ mínima$33^{\circ} \mathrm{C}$ máxima), y siendo distante $132 \mathrm{~km}$ de Quibdó, la capital del Departamento del Chocó, limita al norte con los municipios de Condoto e Itsmina y al este con San José del Palmar, mientras al sur, hace frontera con la antigua población de Sipí (Fundación Las Mojarras 2000:1-2) para conformar una de las regiones más lluviosas del mundo. El soporte económico está representado por actividades mineras, agrícolas y forestales que, jurisdiccionalmente, se hallan asociadas a una distribución territorial conformada por 13 corregimientos y 24 veredas entre las cuales es necesario distinguir un área de 118.400 ha que, según el Consejo Comunitario Mayor, corresponde al "territorio ancestral de las comunidades negras" por tratarse de un área baldía, que ha venido 
siendo ocupada de generación en generación de acuerdo a sus prácticas tradicionales, usos y costumbres; motivo por el cual se ha solicitado justamente al gobierno la titulación colectiva (ibid.:3). De cierta forma, es comprensible que en un momento dado las investigaciones arqueológicas sean importantes en la definición de un respaldo científico que, fortalezca el derecho de esta población sobre la tierra que ha venido ocupando durante siglos. Con un problema semejante se articulan las excavaciones realizadas a partir de 1983 por los mismos indígenas del resguardo de Guambía-Cauca bajo la dirección de Martha Urdaneta: "La investigación nació como propuesta del Cabildo de la Comunidad, enmarcada dentro de un interés por "recuperar" su historia, es decir, por entender su pasado como mecanismo de fortalecimiento de su sociedad actual y de enriquecimiento en la dirección de su futuro" (1988:55).

El largo proceso histórico vinculado a las tradiciones prehispánicas tomó un nuevo rumbo en 1522 cuando las huestes conquistadoras de Pascual de Andagoya provenientes del
Darién, incursionaron en la región sometiendo a los indígenas emberas y noanamaes que ocupaban las zonas ribereñas de esta vertiente hidrográfica (Fundación Las Mojarras 2000:21), en una campaña que desembocaría en la conquista general de lo que ahora es el territorio colombiano a través de los valles interandinos del Cauca y el Magdalena. Es muy probable que entonces arribaran los primeros esclavizados africanos sirviendo de asistentes en las fuerzas españolas, tal como se deduce esporádicamente por medio de la lectura de los cronistas (ver: Escalante 1964). Al ser creada la Gobernación del San Juan (1539) y erigirse la ciudad de Cartago Viejo en el mismo sitio que hoy ocupa Pereira (1540), comienza el afianzamiento político y administrativo de un territorio cuyo potencial aurífero condicionará desde entonces los mecanismos de poblamiento y colonización, de tal forma que hacia 1550 , ya se habla del primer asentamiento de lo que más tarde constituirá la provincia de Nóvita: el Real de Minas de San Felipe (Antón 1994:2), lugar que no está bien definido arqueológicamente pero que fue fundado por Francisco Mosquera,

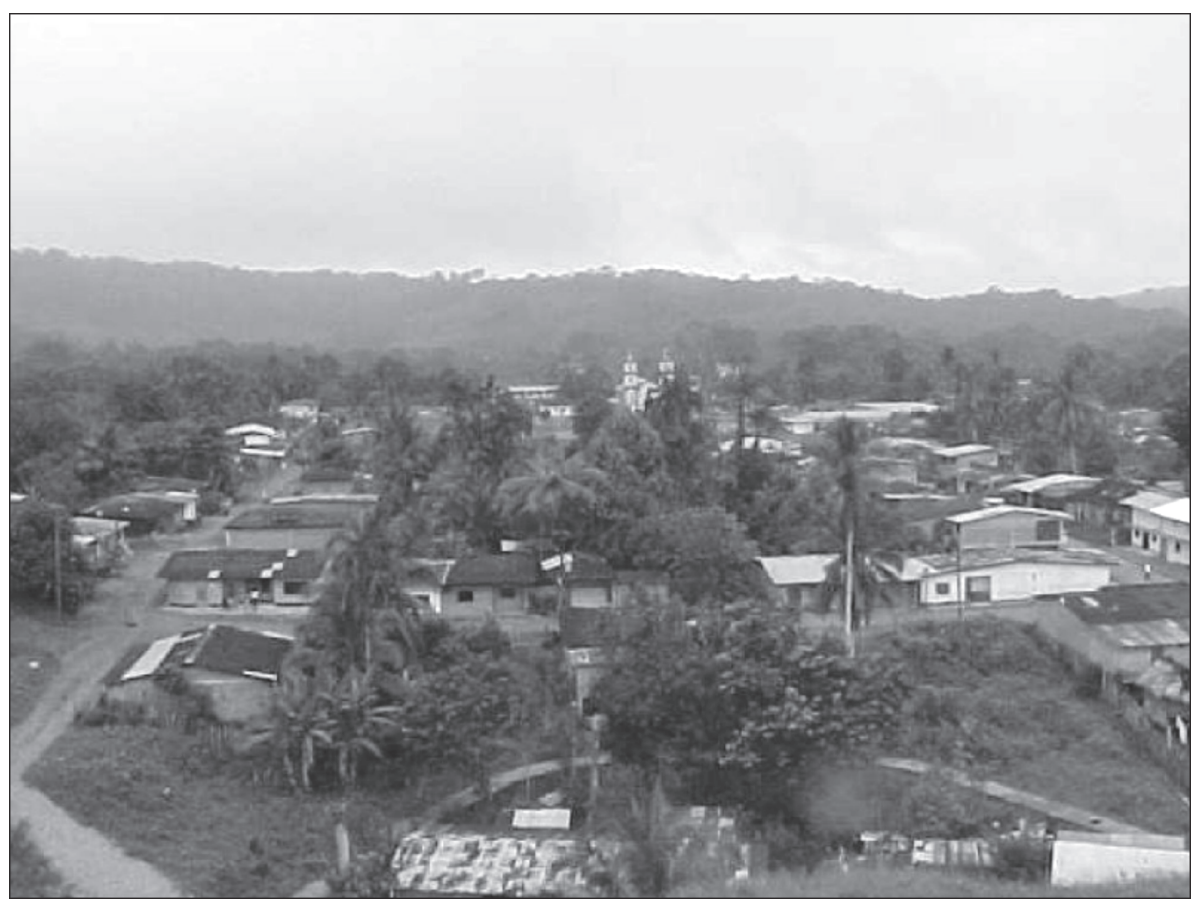

Foto 3. Panorámica de Nóvita. Se observa la iglesia al fondo. 
representante de una elite que terminará por afianzarse en el ámbito jurisdiccional del antiguo Cauca. A este siguió la creación del primer Real de Minas de San Francisco de Nóvita por parte de Melchor Velásquez en 1572 (Fundación Las Mojarras 2000:24), en un sitio diferente al área que abarcó nuestro reconocimiento y que no podemos identificar por ahora.

Con la primera fundación de Toro en territorio chocoano (1573) se consolida la principal vía de comunicación de la época entre el valle geográfico del Río Cauca y el interior de la Costa Pacífica: el Camino de Ita que terminó uniendo las poblaciones de Cartago y Nóvita. Todo esto propiciará la integración de dos aspectos fundamentales en la historia de la Provincia del San Juan: el descubrimiento de un número considerable de yacimientos de oro y platino, la erección de nuevos asentamientos humanos y reales de minas por toda la cuenca del Río Tamaná y la introducción cada vez más numerosa de población africana para laborar en las minas en reemplazo de la mano de obra nativa; así surgió el Real de Minas Sed de Cristo en 1640, y con ese nuevo proceso, comenzarían a ser frecuentes e impactantes las revueltas de los esclavizados en distintos lugares de la región (ibid.22-24), como efectivamente ocurrió en las minas de NeguáCitará, al norte de la zona de estudio (1688).

El traslado y segunda fundación del Real de San Francisco tuvo lugar el 30 de septiembre de 1709 , dando inicio al periodo de mayor auge de la minería y al reforzamiento político y administrativo con la aparición de figuras como alcaldes, capitanes y propietarios de origen caucano, los cuales, en forma simultánea con ese poderío económico, debieron enfrentar los mayores brotes de actividad cimarrona en la región durante un lapso de ciento cuatro años (entre 1721 y 1825) que también, incluye el nombramiento de San Francisco como capital de la nueva Gobernación de Nóvita por disposición de una Real Cédula del 18 de septiembre de 1726 , hecho que le concede aparente autonomía frente a la jurisdicción de Popayán (ibid.:21, 29-30).

En Nóvita, el paisaje selvático está condicionado por terrenos de origen cuaternario que se extienden por toda la cuenca del San Juan y sus afluentes. Poco después de su nacimiento, el Río Tamaná comienza a dar origen a una topografía ondulada que se acentúa más hacia la parte media de su cauce, en la zona de estudio, donde ha tenido lugar la conformación de terrazas aluviales entretejidas con riachuelos que generan valles en forma de "v" y suaves elevaciones con pendientes de areniscas y pizarras muy alteradas, las cuales, por efecto de las altas precipitaciones, un drenaje interno imperfecto y procesos físicos de reducción, han producido suelos extremadamente ácidos de textura franco arcillosa o franco arenosa. Hacia su parte más baja, en proximidades a la desembocadura, el visitante puede acceder a tierras con un relieve plano-convexo sujeto a inundaciones periódicas (ibid.:6-7)

El haber superado las dificultades que implica trasladarse a la zona por una modesta carretera desde el Municipio de Condoto, atravesando en planchón el Río Tamaná por el corregimiento de San Lorenzo, facilitó acceder al sitio arqueológico por un camino de herradura que, en dirección sur, nos condujo a la vertiente de una colina por la cual ascendimos utilizando una trocha angosta y medio cubierta por la vegetación. En la cima, lo primero que se identificó fue un conjunto de canalones tallados en la roca que promediando los $70 \mathrm{~cm}$ de ancho por $30 \mathrm{~cm}$ de profundidad, convergían perpendicularmente hacia la Quebrada Arrastradero, que en forma paralela a otra denominada Tinaja, y en dirección sur-norte, desembocaba en el Río Tamaná a unos pocos metros de allí y en cercanías a una pequeña terraza (Foto 4).

El reconocimiento se llevó a cabo haciendo un recorrido en grupo (alrededor de siete personas, incluido John Antón Sánchez) de estos canalones con el propósito de recolectar el material que había aflorado a la superficie por efecto del lavado que las aguas lluvias hacían periódicamente en el terreno arenoso. Simultáneamente, procedíamos al registro fotográfico y al levantamiento de un croquis del lugar mientras se depositaban los fragmentos cerámicos en bolsas plásticas que distinguían las áreas del recorrido donde, por alguna 


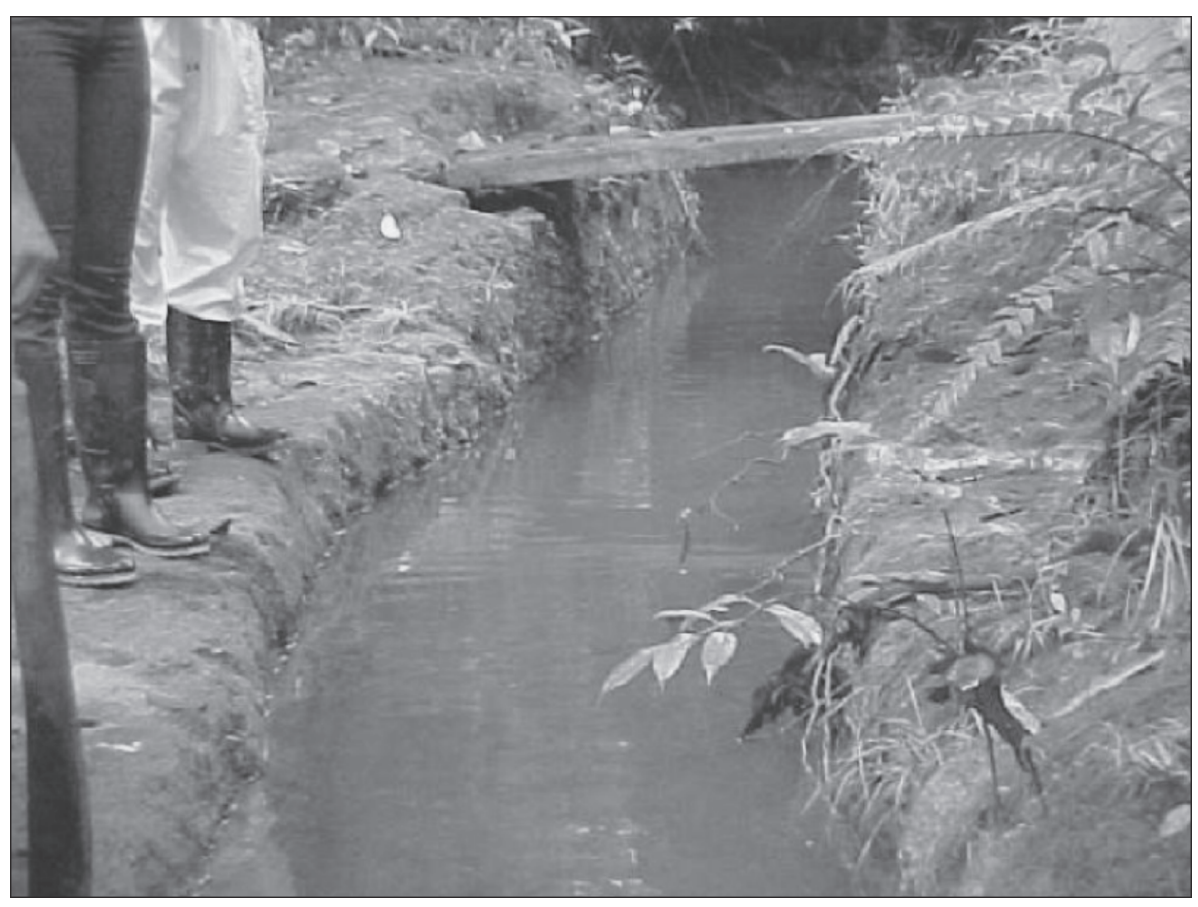

Foto 4. Uno de los canalones observados en el sitio arqueológico.

razón, tendía a concentrarse el material diagnóstico; al mismo tiempo, se cotejaban las observaciones de campo con el registro de la tradición oral que sobre este emplazamiento compartía con nosotros el profesor Iber López como persona especialista en la historia, costumbres y demás valores culturales de la comunidad de Nóvita: labor etnográfica que era indispensable para ubicar el sitio en su contexto espacial, temporal y cultural. El trabajo se completó haciendo la reproducción del perfil estratigráfico del sitio para conocer más a fondo la naturaleza de los suelos y la técnica que los ocupantes utilizaron para la talla de los canalones como parte de un audaz proyecto de ingeniería antigua.

El Plano que se elaboró teniendo en cuenta un dibujo a mano alzada de Iber López (Mapa 1), muestra que las áreas de mayor concentración de vestigios arqueológicos también se distinguen por su distribución respecto de los canalones y el aterrazamiento próximo al río, así como también, de acuerdo a los tipos de material encontrado en estas. Es curioso que en el sector del canalón que bordea la terraza, y encima de la misma, sólo hayamos podido descubrir fragmentos de loza industrial importada inglesa (Foto 5) de la que se han identificado variedad de tipos y formas (Tabla 1), por confrontación con el Catálogo de cerámica colonial y republicana de la Nueva Granada (Therrien et al. 2002).

Mientras tanto, sobre el área que desciende hasta la Quebrada Arrastradero, y en cercanías a otro canalón que nace de ésta, se encontraron cinco fragmentos de una cerámica burda relacionada con formas de uso doméstico como ollas donde se perciben manchas de hollín y cántaros que hacen pensar en la constante necesidad del transporte de líquidos (Foto 6). Ni el tamaño de la muestra recolectada, ni las características inherentes a estos objetos nos permiten asegurar por ahora si esta cerámica es de manufactura indígena y/o afrocolombiana (Tabla 2). Lo único cierto es que al igual que los documentos de archivo, el registro arqueológico parecería generar también una momentánea y aparente "invisibilidad" frente a nuestro intento de ver reflejado allí el 


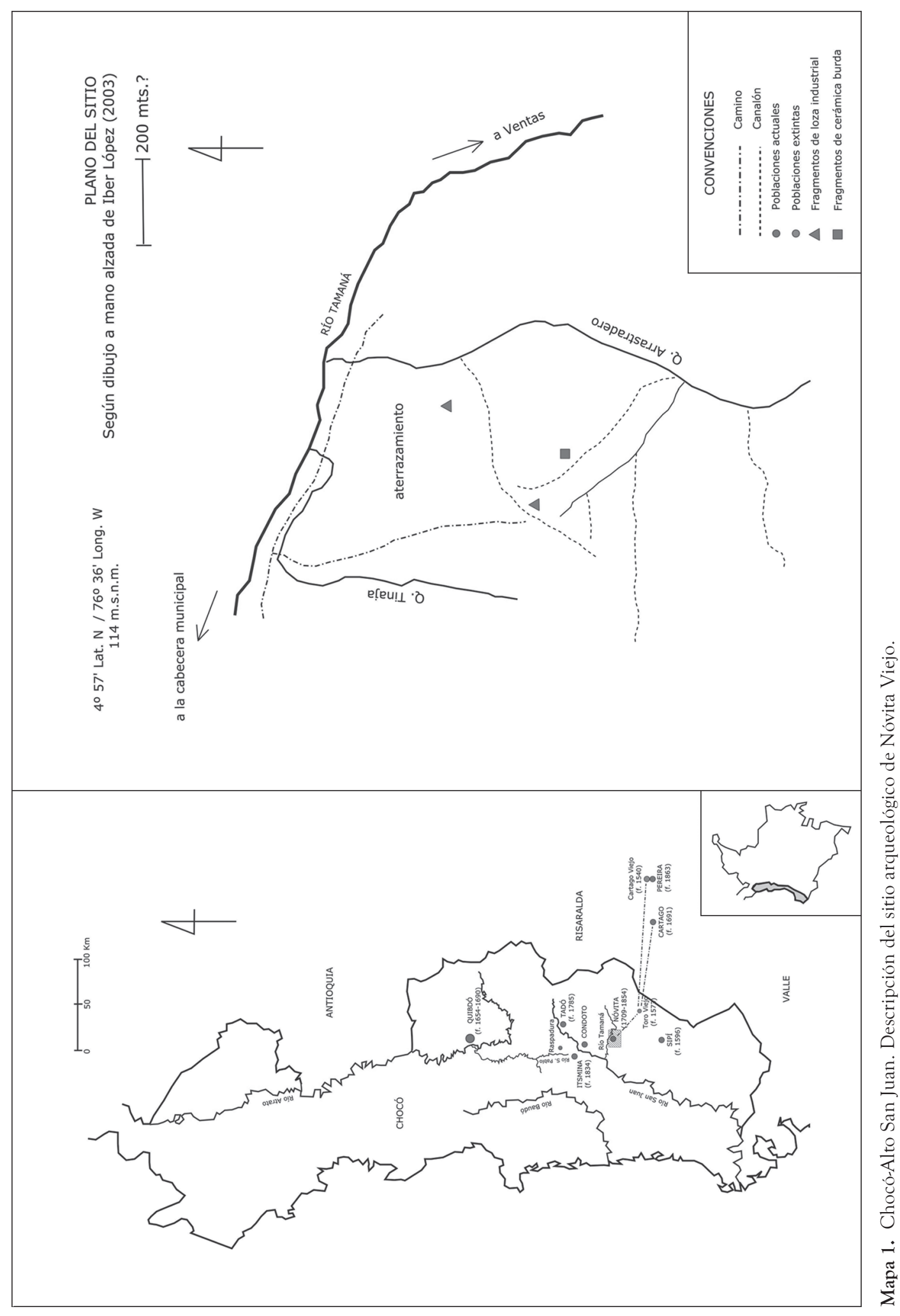




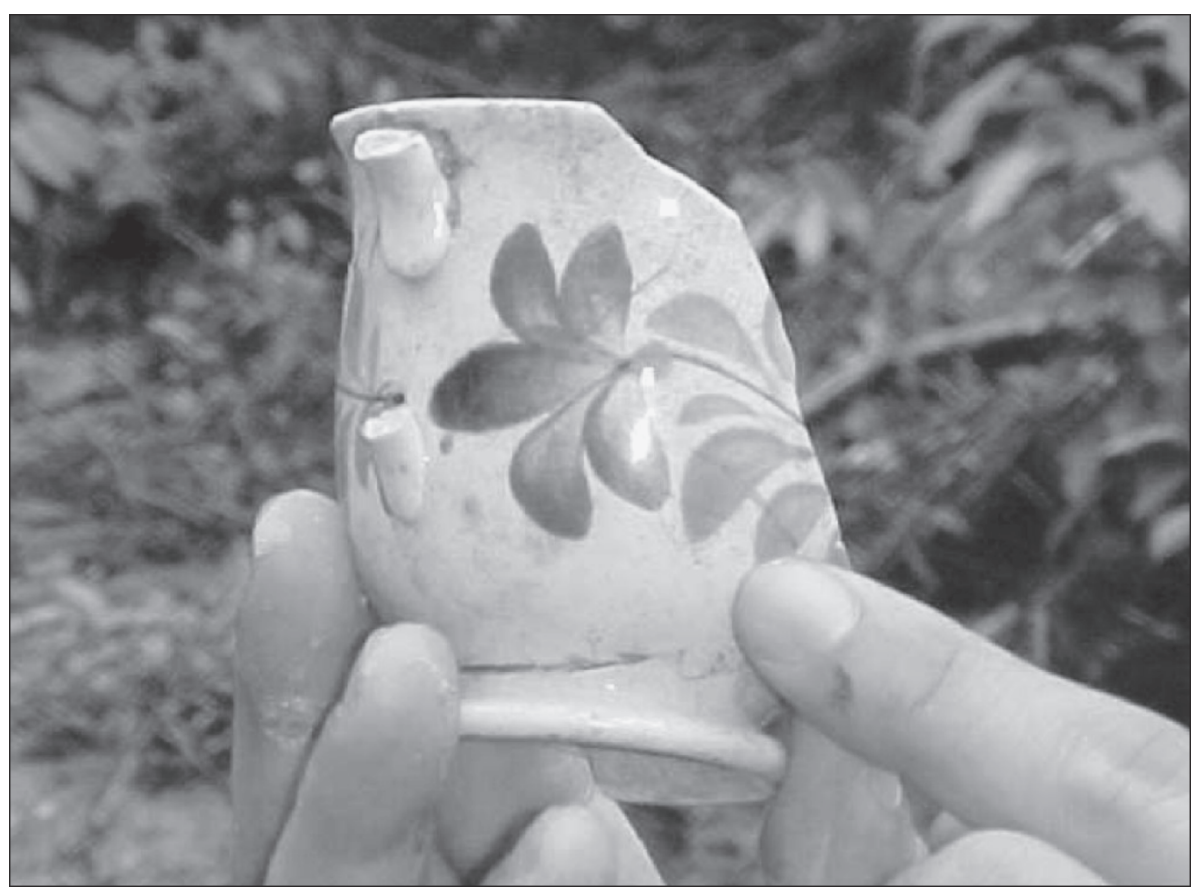

Foto 5. Pocillo recuperado en Nóvita Viejo: tipo decoración floral pintada a mano.

Tabla 1

\begin{tabular}{llr}
\hline \multicolumn{3}{c}{ Loza industrial inglesa. Sitio Nóvita Viejo (Chocó) } \\
\hline \multicolumn{1}{c}{ Formas } & \multicolumn{1}{c}{ Tipos } & Datación \\
\hline \hline Platos & Borde de concha (Shell edged) en loza perlada (Pearlware) & $\pm 1740-1820$ \\
& Impresión por transferencia (Transfer print): oriental azul, floral & \\
Platos y tazas & negro y morado, gótico azul & $\pm 1760-1820$ \\
Pocillos & Decoración floral pintada a mano (Gaudy Dutch) & $\pm 1790-1820$ \\
Platos & Decoración lineal & $\pm 1790-1820$ \\
Azulejos & Decoración con escenas pintorescas & [siglo XVIII] \\
\hline
\end{tabular}

componente afro, tal como lo advertimos en párrafos anteriores. No obstante, el análisis de los vestigios en el contexto espacial del yacimiento podría definir una alternativa de interpretación arqueológica.

Aquella época, y los acontecimientos históricos y sociales que la caracterizan, estuvo determinada por el aumento considerable de una población que en 1778 fue calculada en 2500 habitantes (Peter Wade 1990, citado por: Antón 1994:3-4) distribuidos así: blancos (2\%), esclavizados (39\%), libres (22\%) e indígenas (37\%); demostrando esto no sólo la alta representatividad de los grupos afro, sino también la significativa presencia de los nativos como actores de un modelo social y económico de tipo minero que facilitaba procesos de transculturación. El capitán de ingeniería Juan Jiménez Donoso (1780, f. 7r), quien visitó la zona dos años después del censo, hace un registro de la población afro distinguiendo entre "esclavos" (1129) y "libres" (460), aparte de mencionar que la provincia está regida por un Gobernador Político y Comandante General de Armas acompañado de tenientes, que también actúan como oficiales y corregidores de "indios". En lo referente a la extracción de oro, comenta: 


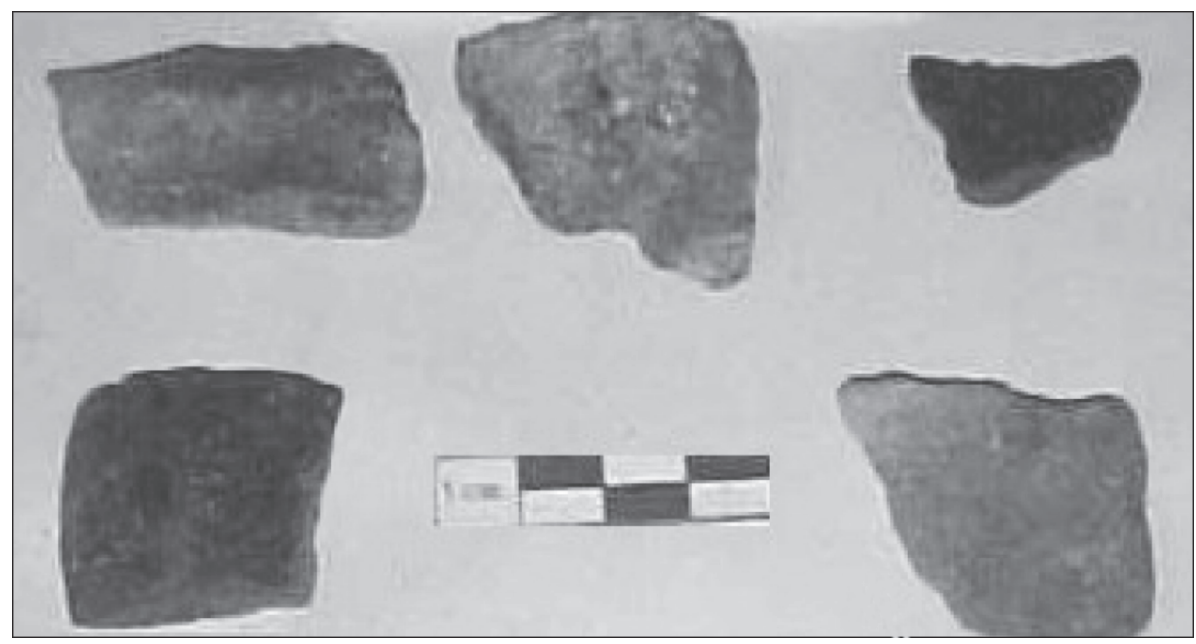

Foto 6. Fragmentos de cerámica burda hallada en el sitio.

Tabla 2

\begin{tabular}{ccccccc}
\hline \multicolumn{6}{c}{ Cerámica burda. Sitio Nóvita Viejo } \\
\hline Formas & \multicolumn{2}{c}{ Pasta } & & Superfície & Decoración & Datación \\
\hline \hline \multirow{3}{*}{$\begin{array}{c}\text { Ollas } \\
\text { Cántaros }\end{array}$} & Mesg. & Cocción & Text. & Gros & & \\
\cline { 2 - 6 } & $\begin{array}{l}\text { Atmósfera } \\
\text { reductora }\end{array}$ & Mediana & $\begin{array}{c}0.6 \mathrm{~cm} \\
1.0 \mathrm{~cm}\end{array}$ & $\begin{array}{c}\text { Áspera. Sin rastro } \\
\text { de engobe }\end{array}$ & Ausente & $\begin{array}{c}\text { Indefin. } \\
\text { [siglo XVIII?] }\end{array}$
\end{tabular}

"Para el laboreo de minas husan de lavatorio, ya de las aguas cuando llueve, o de las albercas y tanques donde la conservan a este fin. Rompida la tierra y desecha a fuerza de mucho trabajo la lavan para que por este medio quede el oro en polvo limpio" (f. 12r). Como lo señala Hidalgo, el oro de Nóvita era acuñado en Popayán y Santafé de Bogotá mientras el platino era utilizado para altares y objetos suntuosos de la aristocracia, a cambio, la región demandaba hachas de hierro, agujas, sal, vino, sebo, aguardiente y vestidos de lujo para los esclavistas (1998:1).

La integración de las evidencias materiales y espaciales del sitio arqueológico nos ha permitido hacer yuxtaposiciones historiográficas, archivísticas y etnográficas que son importantes para entender lo que fue realmente "Nóvita Viejo" en el contexto cultural de la región y de la zona específicamente, permitiendo la formulación de hipótesis en torno a la funcionalidad que ese emplazamiento tuvo durante la Colonia y parte de la República, periodos a los cuales se vinculan los fragmentos de alfarería recuperados en el sector norte al definir un rango cronológico que se ubica entre los años 1740 y 1820. Desde un principio, nuestra interpretación sobre el uso de los canalones vio en las observaciones etnográficas sobre la minería en el Alto San Juan, tan puntualmente descritas por Aquiles Escalante (1971), el recurso analógico para definir la vinculación de este lugar con los reales de minas. El antropólogo destaca la persistencia de los antiguas técnicas de explotación colonial entre las comunidades afrochocoanas a través de procedimientos manuales que implican el uso de instrumentos como almocafres, cachos, barras, totumas y bateas para separar los detritos y obtener la "jagua" o arenilla negra y brillante que contiene los minerales valiosos.

En este proceso, que Escalante señala como "minería de oro corrido", el canalón 
debe construirse al pie de barrancos con valor auroplatinífero haciendo que el agua corra desde pequeñas represas o pilas que se alimentan de las fuentes cercanas o las aguas lluvias, con el propósito de ir lavando la materia prima que se escarba antes de proceder a la separación de los cascotes y al ejercicio del "mazamorreo", actividad tradicionalmente femenina que permite separar el oro del platino a través de movimientos oscilatorios de la batea (ibid.:7882): una descripción etnográfica que coincide mucho con el reporte hecho por Jiménez Donoso en 1780 (op.cit.). Además, según el Tratado de Mineralogía del ingeniero Angel Díaz, comisionado por el virrey para inspeccionar el Real de San Sebastián Quiebralomo (Marmato), el canalón o "socavón de desagüe" necesita ser cavado sobre el terreno con una leve pendiente que varíe dos pulgadas por cada diez varas castellanas de largo (poco más de $80 \mathrm{~m}$ ) que evite el empozamiento del agua (citado en: Hernández de Alba y Espinosa 1991:45), mientras la fuerza de arrastre se controla con la apertura o el cierre gradual de un dispositivo o esclusa ubicada en la pila. Sin embargo, este último elemento de ingeniería que complementa el "entable minero" (Escalante 1971) no fue plenamente identificado durante nuestra labor arqueológica; asunto que expresa la necesidad de continuar las investigaciones en este sitio de "Nóvita Viejo".

En cambio, en lo que corresponde a la relación espacial del yacimiento con la estructura grupal jerarquizada y la organización administrativa que caracterizaba a los reales de minas, encontramos una alta correlación con las fuentes historiográficas cuando hacen referencia al uso de cuadrillas de unos veinte esclavizados dependientes de la autoridad de un mayordomo o administrador generalmente "blanco" o "mulato", que goza de la confianza del dueño y se vale de un capitán o jefe de cuadrilla "negro" para controlar la actividades mineras, en especial la distribución de comida, la disciplina diaria y la recolección semanal de oro y platino destinado a satisfacer el impuesto del Real Derecho de Quintos a razón de 3\% (West / 1952/1972; Whitten y Friedemann 1974:102; Escalante 1971:76). Se deduce también que la expresión "Real de Minas" no indica un sitio particular de explotación, sino un conjunto de "minas" subdivididas en frentes o "cortes" extendidos por un área geográfica determinada y que, como es lógico, eran vigentes mientras no se agotara el potencial aurífero; en caso contrario, ello justificaba el traslado a desaparición de estos asentamientos; lo que efectivamente ocurrió en repetidas ocasiones con la población de Nóvita por toda la cuenca del Río Tamaná. Según Robert West, una cuadrilla podía estar compuesta de un número de individuos que oscilaba entre media docena y ciento cincuenta aproximadamente, estando clasificados como piezas de roza si las actividades se concentraban en el mantenimiento de las chagras que estaban asociadas a los cortes de mina; en seguida agrega: "Dentro de ellos se construían las cabañas de caña y techos de pajas, de los cuales se distinguía la casa del capataz, una capilla pequeña y un centro de acopio que cumplirá las funciones de herrería para fabricar y elaborar los instrumentos de minería” (op.cit.).

También se destaca la importancia de las relaciones que Whitten y Friedemann denominan "socio-sexuales", apoyándose en los estudios de Price (1955) sobre el eventual concubinato entre los administradores con las mujeres esclavizadas (op.cit.:102), algo que nuestra aproximación teórica tiene en cuenta para comprender la producción transcultural a partir de fenómenos de mestizaje entre los ocupantes de estas unidades productivas que, al mismo tiempo, constituían "organizaciones socio-económicas" donde también aparecen comprometidos los grupos indígenas emberas y noanamaes (West /1952/1972). ¿Quiénes elaboraron entonces la cerámica burda hallada en el sector meridional del sitio arqueológico de Nóvita Viejo?.

El análisis cartográfico que nos brinda la observación del "Mapa de la zona entre los ríos San Juan y Tamaná" del año 1781, y que reposa en la sección Colonia del Archivo General de la Nación (Mapoteca 4, 415-A VC.219; publicado por González 1997:11), no sólo permite confirmar en apoyo de la loza industrial inglesa descubierta ( \pm 1740-1820), la hipótesis de West (op.cit.) que plantea la identificación 
de ese sitio con el Real de Minas de San Francisco de Nóvita (1709-1854), sino también la funcionalidad del emplazamiento como un antiguo "corte de mina" perteneciente a esa jurisdicción, y no exactamente como la "ciudad perdida" que ha pretendido verse reflejada en aquellos vestigios; más que eso, se trataría del fragmento de un poblado sin mucha extensión, una especie de caserío o puerto fluvial que aún en 1843 no alcanzaba los cinco mil habitantes (ver: Bolaños 1992:55).

El mapa señala la ubicación de Nóvita hacia la franja izquierda del Río Tamaná, al oeste de la Quebrada Aguaclara (Mapa 2). Desde allí surge un camino que continúa bordeando la ribera hasta acceder a Juntas, lugar donde empieza a bifurcarse para acceder hasta la población de Tadó (en sentido norte), o bien, para dirigirse al Río Ingara (dirección este) y seguir internándose en la Cordillera Occidental, donde supuestamente hacía conexión con la ruta que llevaba a la nueva ciudad de Cartago, trasladada en 1691 desde su primitiva ubicación hasta el actual Departamento de Valle del Cauca (Cano, Acevedo y López 2001:79-80). Lo que más interesa a nuestras conclusiones tiene que ver con el asentamiento mismo, pues se observa que la población de Nóvita, señalada con un círculo y una cruz (curato), está unida por una especie de trocha con otra área denominada "Bodega", que por estar más próxima al río, se yuxtapone espacialmente con la población actual, ${ }^{6}$ mientras que el sitio arqueológico podría corresponder con un sector marginal del antiguo San Francisco de Nóvita, lo cual indicaría que el yacimiento más importante aún está por descubrirse al interior de la zona, un poco más al sur.

De esa forma, podemos concluir reiterativamente que el sitio que hasta el momento se denomina "Nóvita Viejo" corresponde en realidad a un "corte de mina" donde la distribución y las características de las evidencias materiales reflejan hipotéticamente su

(6) Ubicada por cierto, en proximidades a una "Quebrada Bodega”. estructura jerarquizada: un espacio destinado a los administradores o mayordomos (aterrazamiento con alta presencia de loza industrial inglesa) y otro restante para los individuos obligados a extraer la riqueza mineral, los verdaderos artífices de los canalones y toda la red de ingeniería hidráulica y, seguramente, de la cerámica burda que descubrimos en cercanías a la Quebrada Arrastradero. ¿Quiénes fueron?. El sentido común parecería creer que fueron los antiguos afrochocoanos, con o sin influencia cultural indígena $\mathrm{y} / \mathrm{o}$ europea, pero la rigurosidad científica nos obliga a ser prudentes a la altura de una investigación que apenas inicia y de la cual el público tuvo conocimiento gracias a las notas periodísticas asociadas al desarrollo del simposio: Etnicidad Afrocolombiana. Visión Endémica III, realizado en la ciudad de Manizales durante el X Congreso de Antropología en Colombia (Anónimo 2003).

Así, la ventaja económica de la explotación minera recaía verdaderamente en miembros de la elite caucana como Francisco Arboleda y Tomasa de Ibargüen, cuya parentela aún defendía intereses en la localidad aunque se hubiese consolidado el proceso independista que dio origen a la República de la Nueva Granada, según consta en un documento firmado en Nóvita que reposa en el Archivo Histórico de Cali, relativo al poder que Francisco Paterson Sander otorga a José Antonio Borrero para que lo represente con anuencia de su esposa Juana María Ibargüen (AHC, Notaría Segunda, Tomo 1, Nos. 1-167, folio 49. 1834). En consecuencia, la situación para los grupos afro no era muy distinta a finales del siglo XIX en las haciendas y emporios industriales del Cauca, tal como puede definirse con ayuda de los registros fotográficos de esta época (Foto 7); muchos de los antiguos esclavizados debieron permanecer en sus lugares de trabajo al no tener otra alternativa de subsistencia, pues uno de ellos, Sixto Borrero, murió anciano en la hacienda Piedechinche (El Cerrito-Valle) mostrando a los nuevos colonos de la zona las "marcas" impuestas por los esclavistas terratenientes (López 2002:262-263).

La propuesta de continuar adelantando un programa de arqueología para y desde las 


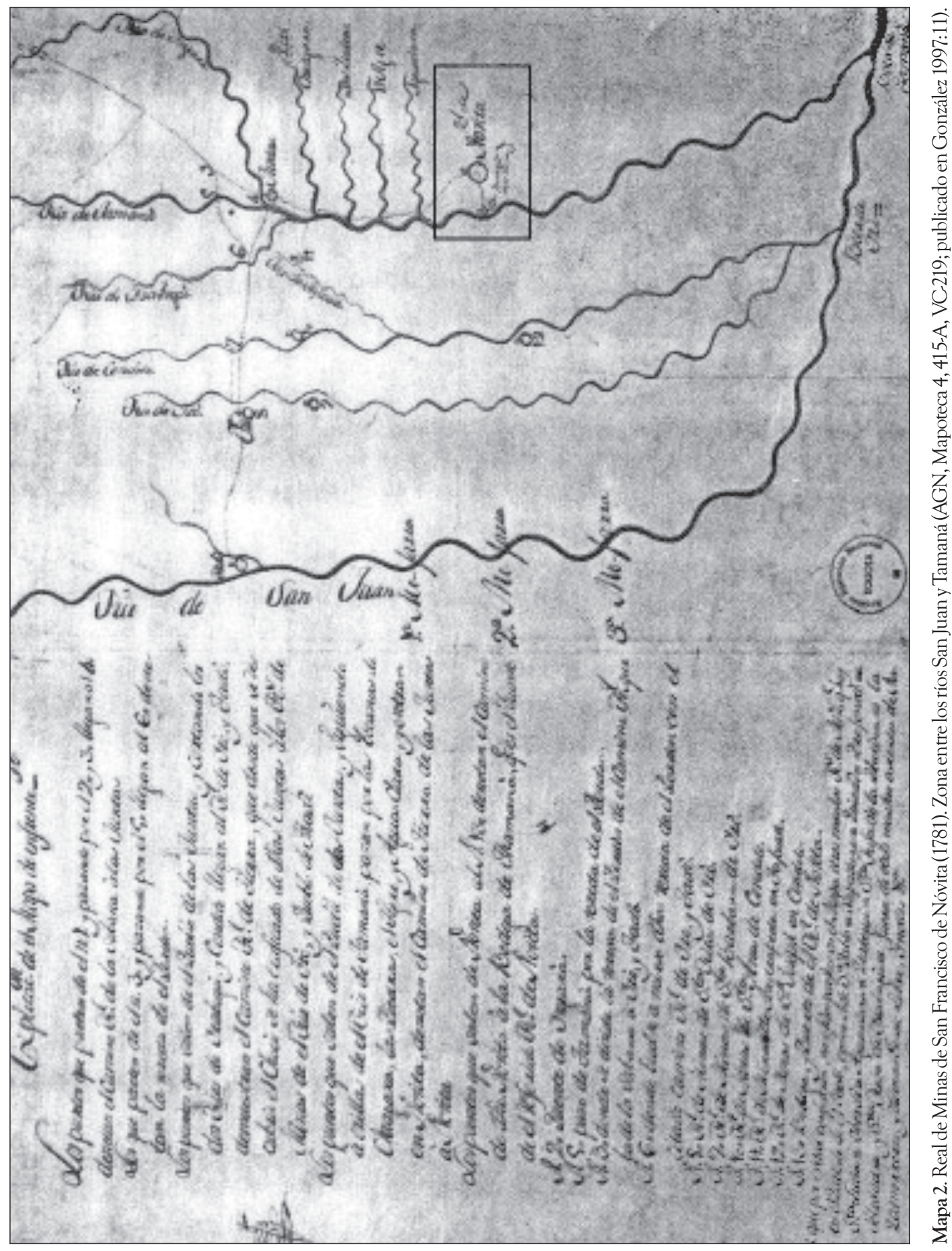




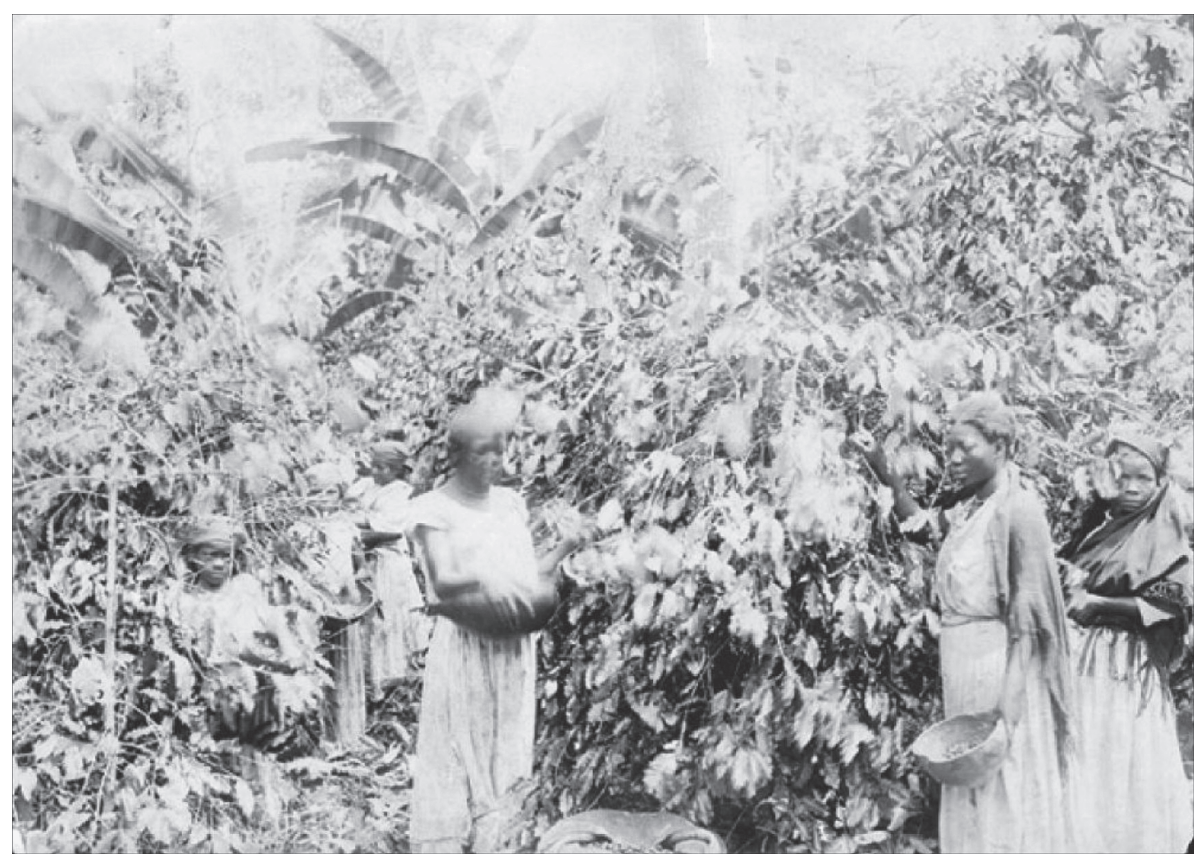

Foto 7. Mujeres cosechando café en 1893 (propiedad del Ingenio Manuelita). En: Archivo del Patrimonio Fotográfico y Fílmico del Valle del Cauca (Gobernación, 2000)

comunidades afrocolombianas, deberá ganar vigencia a través de un desarrollo metodológico, que desafíe los obstáculos que implica hacer exploraciones en selvas tropicales húmedas con el agravante de los problemas de orden público en casi todo el Chocó Biogeográfico, específicamente en la subregión del San Juan. En este tipo de labor arqueológica se hace estrictamente necesario definir la ubicación de los antiguos emplazamientos (reales de minas) extendidos a lo largo de la cuenca del Tamaná, al tiempo que la problemática local representada por la antigua población de Nóvita se articula regionalmente con fundaciones más antiguas como Sipí y el primer emplazamiento de ToroValle, vestigios que fueron localizados a principios del siglo XX y que terminaron perdiendo importancia frente al concepto reduccionista de la arqueología colombiana como arqueología exclusivamente indígena. De esa forma, el estudio sobre la dinámica social y cultural en la región durante la Conquista, la Colonia y la República, sólo deberá ser explorada como parte de un contexto histórico dependiente de la antigua jurisdicción de
Popayán, lo cual involucra la ruta que unía a las viejas poblaciones de lo que hoy es el norte del Valle y el Viejo Caldas con el San Juan a través de caminos olvidados.

Frente a ese panorama, es indispensable articular, revisar y confrontar la información historiográfica con una rigurosa búsqueda y consulta de fuentes primarias que aguardan en los archivos: General de la Nación, Central del Cauca, Histórico de Cali, Parroquial de Nóvita, Catedral de Itsmina, Catedral de San Francisco de Asís de Quibdó (bastante afectado por los incendios durante el siglo XIX), Catedral de Cartago y Parroquial de Toro-Valle, principalmente. El éxito de las fases de prospección y excavación arqueológica dependerían entonces de una reconstrucción cartográfica que genere una alta probabilidad en la ubicación de los sitios, antes que exponer al fracaso una búsqueda desorientada y costosa en medio de un paisaje selvático donde los agentes patógenos acechan con frenesí. El curso de las investigaciones debería estar integrado, como señalamos arriba, a ejercicios de participación comunitaria que revitalicen el 
sentido de pertenencia a la región, a través del agradable proyecto de rescate de las tradiciones sanjuaneñas con ayuda de cartillas, talleres y actividades de campo que permitan ir definiendo el trabajo arqueológico como una actividad social, antes que un simple mecanismo para la recuperación de objetos exóticos.

El colapso del antiguo Real de Minas de San Francisco de Nóvita, estuvo precedido por un descenso demográfico que se explica por la conjunción de varios factores como: una alta tasa de mortalidad debida probablemente a epidemias de fiebres tropicales, conflictos de los mineros en medio de la usura y el contrabando en una región con perdida de autoridad por causa de las guerras civiles, el impacto del cimarronismo y la manumisión (ver: Antón 1994:8-11; Jiménez 1780; Fundación Las Mojarras 2000:30), pero ante todo, por haber sido abolida la esclavitud a partir del $1^{\circ}$ de enero de 1852. La "ciudad bastante grande y famosa por minas de oro", cuna de presidentes de la República y miembros de familias esclavistas cuya memoria iconográfica vive en las salas del Museo Nacional de Colombia; la capital de la provincia y puerto comercial a donde Jorge Enrique Isaacs, padre el autor de María, transportó sus mercancías de bayetas y lienzos ("todo seco y sano") para Miguel González Otoya en 1842 (En: AHC, Notaría Segunda, Tomo 1, Nos. 1-49, folio 199r. 18411842), pasó a ser descrita por la Comisión Corográfica en 1851 como una población donde: “...no hay escuela, no hay iglesia, no hay establecimiento público ni privado, ni talleres, ni conventos, ni oficinas, casi ni gente. Sus habitantes andan casi desnudos, con pies en el suelo, una camisa de listado y unos altos y estrechos pantalones de dril". Quizá, con las reformas constitucionales y la creación de nuevos municipios, los últimos habitantes del Real de Minas se vieron obligados a ocupar distintas zonas en toda la cuenca del Río Tamaná, dando paso a una transformación demográfica que condicionó el surgimiento de la actual San Jerónimo de Nóvita en el año de 1854 (Hidalgo 1998), atrás, los antiguos noviteños dejaron sepultados en la selva los vestigios materiales e "invisibles" de un pasado de explotación y abuso, que se ha convertido en leyenda para dar origen a imaginarios sociales que no logran precisar en todos sus aspectos el verdadero significado de lo que ha sido la esclavitud.

Fragmentos de esa realidad histórica hacen parte del inventario parroquial: "Esta es la mesa que perteneció a Tomasa de Ibargüen traída desde Nóvita Viejo. ¿iPesa!?: ¡lo que usted quiera!", afirma el Presbítero Gildardo Alzate mientras procede a señalar un retablo de plata que tiene repujada una asociación simbólica del Real de Minas de San Francisco (Entrevista. 4 de enero de 2003). Fuera del templo, uno de los objetos más curiosos de esa época se encuentra ubicado en el centro de la plaza; es una lápida semi-ovalada hecha en basalto aparentemente destinada a la tumba de Francisco Eusebio Martínez Bueno (1800?1841), antiguo gobernador del Chocó nacido allí en Nóvita y que falleció de un balazo en Andágueda tratando de someter una rebelión contra el gobierno (Gaitán 1995:557-559). Según la leyenda, al conocerse la muerte de Martínez, esa lápida fue traída desde Cartago atravesando la cordillera hasta acceder a Nóvita por el Río Tamaná, pensando que la muerte del gobernador había ocurrido allí. Al darse cuenta de su error, y siendo ya bastante conscientes del enorme peso, optaron por dejarla abandonada en la zona hasta ser recuperada muchos años después ${ }^{7}$ (Foto 8). La inscripción, que ya no es legible por el efecto degradante de la lluvia y el abandono, sólo puede conocerse en la localidad gracias a la tradición del profesor Iber López: “"Caminante, ve y dile a la Nueva Granada que he muerto por obedecer sus leyes..." (Entrevista. 4 de enero de 2003).

Tres años después (14 de noviembre de 1844), otro miembro de ese extenso linaje aristocrático, Carlos Martínez, bautizaba de

(7) Hay que destacar cómo la leyenda hace "invisible" la identidad de las personas que "directamente" soportaban el peso de la lápida hasta el sitio de Nóvita, las cuales podrán deducirse en el contexto histórico y social que hemos descrito en este trabajo. 


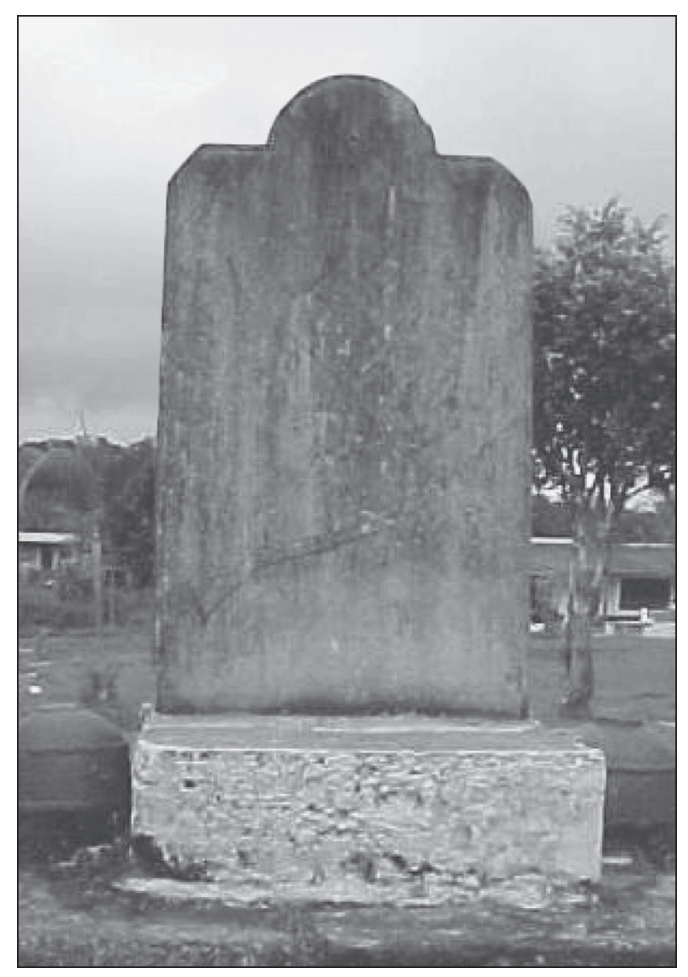

Foto 8. Lápida de Francisco Eusebio Martínez Bueno (1800?-1841) en el centro de la plaza de Nóvita.

emergencia al hijo de una pareja de esclavizados en su hacienda El Alisal, cercana a la aldea de El Cerrito-Valle. En un suceso cotidiano que puede generar distintas interpretaciones, el esclavista buscaba impedir a través de este rito católico que el alma de la criatura en peligro de muerte, quedase atrapada en el "limbo" para toda la eternidad (López 2002: 99-100). Cuando Juan Angel Molina, atravesó el umbral de las habitaciones de Luciano Rivera y Garrido para narrarle aventuras que a él mismo le parecían legendarias, aquel año de 1897, quizá iba meditando un poco sobre reinos africanos perdidos en el tiempo similares a los descritos por Jorge Isaacs en su novela María:

"Siendo niña todavía cuando Sinar vino como siervo a casa del vencedor de Orsué, la cautivó al principio la digna mansedumbre del joven guerrero, y más tarde su ingenio y hermosura. Él le enseñaba las danzas de su tierra natal, los amorosos y sentidos cantares del país de Bambuk; le refería las maravillosas leyendas con que su madre lo había entretenido en la niñez; y si algunas lágrimas rodaban entonces por la tez úvea de las mejillas del esclavo, Nay solía decirle:

-Yo pediré tu libertad a mi padre para que vuelvas a tu país, puesto que eres tan desdichado aquí.

Y Sinar no respondía; más sus grandes ojos dejaban de llorar y miraban a su joven señora de manera que ella parecía en aquellos momentos la esclava" (Isaacs / 1867/2001: 150-151).

¿Quiénes elaboraron la cerámica burda descubierta en el sector meridional del sitio arqueológico de "Nóvita Viejo"?. Aunque el corazón dice que fueron los esclavizados del Real de Minas, lastimosamente aún no podemos demostrarlo con exactitud, quizá alguien lo pueda hacer un día; pero lo cierto, es que la experiencia que hemos compartido aquí trae consigo un gran mensaje: aprender a valorar lo pequeño, aprender a ver lo grande en lo pequeño, recordar una máxima del profesor Jesús María Botero del Servicio Nacional de Aprendizaje. SENA, a quien conocí en Medellín en el año de 1988 cuando era estudiante de mecánica. Ignoro si él fue el autor, o retomó esa frase de alguien a quien desconozco, pero decía: "Muchachos: No se olviden que de los pequeños detalles... están hechas las grandes catedrales".

\section{Agradecimientos}

El autor quiere rendir un sincero agradecimiento a las personas e instituciones que facilitaron el desarrollo de una idea que en su etapa inicial, surgió como respuesta a la fe que un grupo de académicos y líderes de las comunidades de Nóvita y Condoto depositaron en el enfoque alternativo que ofrece una arqueología afrocolombiana como elemento de su propia reconstrucción histórica. De esa manera, agradezco a mi colega John Antón Sánchez, a su familia y a la Fundación Las Mojarras de Condoto, la cordial invitación para llevar a cabo el 
reconocimiento en la zona de estudio, así como también, a Rafael Pereachalá Alumá por haber compartido su entusiasmo y valiosos conocimientos sobre la historia y geografía de su Chocó nativo, refugio cultural de la humanidad que, ama y defiende con perseverancia y heroísmo. En Nóvita, al presbítero Gildardo Alzate y al profesor Iber López por su voluntad de compartir con nosotros, tantos secretos ancestrales del Real de Minas de San Francisco. Por último, hago extensiva mi gratitud a los Drs. Betty Meggers del Smithsonian Institution de Washington D.C. y Pedro Paulo Funari de la Universidade Estadual de Campinas-Brasil, por sus valiosos aportes bibliográficos e investigativos a nuestro proyecto desde aquella época estudiantil.

LÓPEZ C., L.F. The invisible of the Royal of Mines: reflections and offers concerning the archaeological site of Nóvita Viejo, Alto San Juan-Chocó (Colombia). XVIII ${ }^{\text {th }}$-XIX ${ }^{\text {th }}$ centuries. Revista do Museu de Arqueologia e Etnologia, São Paulo, 17: 391-417, 2007.

Abstract: Choco Department, in Colombia, is an area characterized by both conflict and potential. Archaeological fieldwork at the ancient Royal Mines at San Francisco de Nóvita enabled us to reach the interests of affected communities and thus to broaden our outlook. The site is now abandoned in the jungle, but still resonates in local lore and archives. The archaeological study is also useful for rescuing the rich cultural heritage in the area. Most of all, it empowers local people. This paper addresses theoretical and methodological issues, studying primary sources and international literature.

Keywords: Nóvita Viejo - Real de Minas - Esclavizados - Transculturación Afro-Colombian archaeology.

\section{Referencias bibliográficas}

AHC. ARCHIVO HISTÓRICO DE CALI

1834 Notaría Segunda, Tomo 1, Nos. 1-167, folio 49.

1841-1842Notaría Segunda, Tomo 1, Nos. 1-49, folio $199 \mathrm{v}$.

\section{ANÓNIMO}

2003 Vigencia de la afrocolombianidad. Hallan vestigios de Nóvita Viejo. La Patria, 28.998: 6a.

\section{ANTÓN SÁNCHEZ, J.}

1994 Manumisión y proceso de libertad en la ciudad colonial de Nóvita. 1849- 1850 (manuscrito).

2002 Anotaciones para una arqueología afrocolombiana (manuscrito).

BOLAÑOS LEMUS, N.

1992 La formación del Estado y la problemática regional. Un estudio de caso, el Chocó siglos
XIX y XX. Santafé de Bogotá: Universidad de los Andes. Centro Interdisciplinario de Estudios Regionales. CIDER.

BOTERO RESTREPO, J.

1968? Andágueda. Medellín: Editorial Bedout. CANO, M.; ACEVEDO, A.; LÓPEZ, C.

2001 Encuentro con la historia: Catedral de Nuestra Señora de la Pobreza. Pereira: Fundación Autónoma pro-restauración de la Iglesia Catedral Nuestra Señora de la Pobreza.

CONSEJO NACIONAL DE LA CULTURA.

1993 Presencia Africana (Catálogo). Caracas:. Fundación Museo de Ciencias. Centro de Estudios Africanos y Afroamericanos Juan Liscano. Fundación Conmemorativa Bessie H. Scott. 
ENTREVISTA CON EL PROFESOR IBER LÓPEZ

2003 En el sitio arqueológico de Nóvita Viejo (4 de enero).

ENTREVISTA CON EL PBRO. GILDARDO ALZATE

2003 En su despacho de la Parroquia de San Jerónimo de Nóvita (4 de enero).

ENTREVISTA CON ESTHER MOSQUERA

2003 En su residencia de San Pablo Adentro, Itsmina-Chocó (6 de enero).

ESCALANTE, A.

1964 El negro en Colombia. Bogotá: Universidad Nacional de Colombia. Facultad de Sociología.

1971 La minería del hambre (Condoto y la Chocó Pacífico). Barranquilla: Ediciones Universidades Medellín, Córdoba y Simón Bolívar.

FERGUSON, L.

1992 Archaeology and Early African America. 1650-1800. Washington and London: Smithsonian Institution Press.

FUNARI, P.P.

1993 Memoria histórica e cultura material. Revista Brasileira de História, 13 (25-26): 17-31.

1994a La cultura material y la arqueología en el estudio de la cultura africana en las Américas. América Negra, 8: 33-47.

1994b Rescuing ordinary people's culture: museums, material culture and education in Brazil. P. G. Stone; B. L. Molyneaux (Eds.) The present past: heritage, museums and education. London and New York, Routledge: 121-136.

1995 Mixed features of archaeological theory in Brazil. P. J. Ucko (Ed.) Theory in Archaeology: A world perspective. London, Routledge: 237-250.

1996 Novas perspectivas abertas pela arqueología da Serra da Barriga. L. M. Schwarcz (Coord.) Curso sobre cultura afro-brasileira. Departamento de Historia. Instituto de Filosofia e Ciencias Humanas da Universidade Estadual de Campinas: 1-20.

\section{FUNDACIÓN LAS MOJARRAS}

2000 Anotaciones puntuales acerca del Municipio de Nóvita. Condoto-Chocó.

GAITÁN, E.

1995 Grandes del Chocó. Desde Colón hasta hoy. Tomo II. Medellín: Alas libres.

GOBERNACIÓN DEL VALLE DEL CAUCA

2000 Archivo del patrimonio fotográfico y filmico del Valle del Cauca. Cali: Secretaría de Cultura y Turismo.
GONZÁLEZ ESCOBAR, L.

1997 Chocó en la cartografía histórica. De territorio incierto a departamento de un pais llamado Colombia. Quibdó: Banco de la República. Área Cultural.

HALEY, A.

/1976/1978 Raices: historia de una familia americana. Traducción de Rolando Costa Picazo. Buenos Aires: Emecé.

HERNÁNDEZ DE ALBA, G.; ESPINOSA, A.

1991 Tratados de minería y estudios geológicos de la época colonial. 1616-1803. Bogotá: Academia Colombiana de Ciencias Exactas, Físicas y Naturales. Colección Enrique Pérez Arbeláez, 4.

HIDALGO, E.

1998 QQue sabe usted sobre San Jerónimo de Nóvita?. Chocó Siete Días, 171:4.

ISAACS, J.

/1867/2001María. Santafé de Bogotá: Sol 90.

JIMÉNEZ DONOSO, J.

1780 Relación de las provincias del Chocó, Zitará, Nóvita y del rio Atrato. Santafé de Bogotá: Banco de la República. Biblioteca Luis Angel Arango. Libros Raros y Manuscritos.

LA ROSA CORZO, G.

1996 Rescate de Olórum (Estudio de arqueología afroamericana). América Negra, 12: 39-57.

LOBO GUERRERO, J.

2001 Respuestas culturales al sistema de dominación indígena durante el periodo colonial. Un estudio de Arqueología Histórica en Gachantivá Viejo: pueblo de indios (Tesis). Bogotá: Universidad de los Andes. Departamento de Antropología.

LOPEZ CANO, L.F.

1993 Propuesta para una arqueología de las comunidades afrocolombianas. Ponencia presentada durante el III Encuentro de Estudiantes de Antropología. Popayán: Universidad del Cauca.

2002 La tumba de María Isaacs: génesis y desarrollo de una leyenda vallecaucana. Bogotá: Ministerio de Cultura. Premios Departamentales.

MANDINGA (SEUD.)

1997 En busca del pasado afrochocoano. Soledad del Tajuato: urge rescate histórico y arqueológico. La Prensa del San Juan, 1: 7.

MANSILLA CASTAÑO, A.

2000 Patrimonio afroamericano en Brasil: arqueología de los quilombos. Departamen- 
to de Prehistoria. Universidad Complutense de Madrid. En línea: http:// www.ucm.es/info/arqueoweb/ word/2(2)/mansilla.doc.

MOSQUERA PEREA, N.

2003 Diez tesis afrocolombianas e indígenas. Medellín: Úryco.

NAVARRETE, M.C.

2003 Cimarrones y palenques en el siglo XVII. Cali: Universidad del Valle.

NEIRA, A.

2002 Agonía sin fin. Semana, 1045: 32-40.

PEREACHALÁ ALUMÁ, R.

2003 El problema del etnónimo. Ponencia presentada durante el simposio: Etnicidad Afrocolombiana, Versión Endémica III. Manizales: X Congreso de Antropología en Colombia.

PETERSEN, J.B.; WATTERS, D.R.

1988 Afro-montserratian ceramics from the Harney Site Cemetery, Montserrat, West Indies. Annals of Carnegie Museum, 57: 167-187.

PRICE, T.J.

1955 Saints and spirit: a study of differential acculturation in Colombian negro communities. Ph.D. dissertation. Evanston, Illinois: Northwestern University.

SCHWEGLER, A.

1991 Hacia una arqueología afrocolombiana: restos de tradiciones religiosas bantúes en una comunidad negroamericana (manuscrito).

SINGLETON, T.A.

1988 An Archaeologycal Framework for Slavery and Emancipation. 1740-1880. M. P. Leone and P.B. Potter (Eds.) Historical Archaeology in the Eastern United States, Jr. Washington and London, Smithsonian Institution Press: 345-370.
STEMPER, D.M.; SALGADO, H.

1993a Metalurgia prehispánica y colonialrepublicana en el pacífico colombiano. Revista Colombiana de Antropología, 30: 59-89.

1993b Tres milenios de historia con base en la arqueología del Pacífico. P. Leyva (Ed.) Colombia Pacífico, Tomo 1. Santafé de Bogotá, Fondo FEN: 272-291.

SUAZA ESPAÑA, M.A.

1995 Una aproximación desde la perspectiva arqueológica a la problemática cimarrona (Tesis). Bogotá. Universidad Nacional de Colombia. Departamento de Antropología.

THERRIEN, M.

1991 Basura arqueológica y tecnología cerámica. Estudio de un basurero de taller cerámico en el resguardo colonial de Ráquira, Boyacá (Tesis). Bogotá: Universidad de los Andes. Departamento de Antropología.

THERRIEN, M.; UPRIMMY, E.; LOBO G., J.; SALAMANCA, M.; GAITÁN, F.; FANDIÑO, M.

2002 Catálogo de cerámica colonial y republicana de la Nueva Granada. Bogotá: Banco de la República. Fundación de Investigaciones Arqueológicas Nacionales.

URDANETA FRANCO, M.

1988 Investigación arqueológica en el resguardo indígena de Guambía. Boletín del Museo del Oro, 22: 55-81.

WEST, R.C.

/1952/1972 La minería de aluvión en Colombia durante el periodo colonial. Bogotá: Imprenta Nacional.

WHITTEN, N.E.; FRIEDEMANN, N.S.

1974 La cultura negra del litoral ecuatoriano y colombiano: un modelo de adaptación étnica. Revista Colombiana de Antropología, 17: 75-115. 